RULES, DISCRETION, AND CORRUPTION IN PROCUREMENT:

EVIDENCE FROM ITALIAN GOVERNMENT CONTRACTING

Francesco Decarolis

Raymond Fisman

Paolo Pinotti

Silvia Vannutelli

WORKING PAPER 28209 
NBER WORKING PAPER SERIES

\title{
RULES, DISCRETION, AND CORRUPTION IN PROCUREMENT: EVIDENCE FROM ITALIAN GOVERNMENT CONTRACTING
}

\author{
Francesco Decarolis \\ Raymond Fisman \\ Paolo Pinotti \\ Silvia Vannutelli \\ Working Paper 28209 \\ http://www.nber.org/papers/w28209 \\ NATIONAL BUREAU OF ECONOMIC RESEARCH \\ 1050 Massachusetts Avenue \\ Cambridge, MA 02138 \\ December 2020, Revised February 2023
}

We thank seminar audiences at Kellogg School of Management - Northwestern University, University of Montreal and SIOE 2019. We also thank Juan Ortner and Giancarlo Spagnolo for helpful comments. Decarolis gratefully acknowledges financial support from the European Research Council (ERC-2015-StG-679217). The views expressed herein are those of the authors and do not necessarily reflect the views of the National Bureau of Economic Research.

NBER working papers are circulated for discussion and comment purposes. They have not been peer-reviewed or been subject to the review by the NBER Board of Directors that accompanies official NBER publications.

(C) 2020 by Francesco Decarolis, Raymond Fisman, Paolo Pinotti, and Silvia Vannutelli. All rights reserved. Short sections of text, not to exceed two paragraphs, may be quoted without explicit permission provided that full credit, including $\odot$ notice, is given to the source. 
Rules, Discretion, and Corruption in Procurement: Evidence from Italian Government Contracting Francesco Decarolis, Raymond Fisman, Paolo Pinotti, and Silvia Vannutelli

NBER Working Paper No. 28209

December 2020, Revised February 2023

JEL No. D72,D73,H57,K42

\section{ABSTRACT}

The benefits of bureaucratic discretion depend on the extent to which it is used for public benefit versus exploited for private gain. We study the relationship between discretion and corruption in Italian government procurement auctions, using a confidential database of firms and procurement officials investigated for corruption by Italian enforcement authorities. We show that discretionary procedure auctions (those awarded based on negotiated rather than open bidding) are associated with corruption only when accompanied by limits to competition. We further show that, while these "corruptible" discretionary auctions are chosen more often by officials who are themselves investigated for corruption, they are used less often in procurement administrations in which at least one official is investigated for corruption. These findings fit with a framework in which more discretion leads to greater efficiency as well as more opportunities for theft, and a central monitor manages this trade-off by limiting discretion for high-corruption procedures and locales. Overall, our results suggest that competition may allow procurement authorities to extract the benefits of discretion while limiting the resultant risks of abuse.

Francesco Decarolis

Bocconi University

Via Sarfatti 25

Milan, 20136

Italy

and EIEF

francesco.decarolis@unibocconi.it

Raymond Fisman

Department of Economics

Boston University

270 Bay State Road, 304A

Boston, MA 02215

and NBER

rfisman@bu.edu
Paolo Pinotti

Bocconi University

Via Rontgen 1

20136 Milan

ITALY

and fRDB and also BAFFI-CAREFIN Centre

paolo.pinotti@unibocconi.it

Silvia Vannutelli

Kellogg Global Hub

Northwestern University

2211 Campus Drive

Evanston, IL 60208

and NBER

silvia.vannutelli@northwestern.edu 


\section{Introduction}

Governments often face a trade-off in the oversight and constraints they impose on lower-level bureaucrats in carrying out their functions. Officials may use discretion to better serve the public's interests, or exploit it for personal gain. The appropriate level of discretion depends on the benefits of an agent's informational advantage relative to the costs from his exploiting discretion for personal gain. From a public welfare perspective, the agency problem is complicated by yet another layer of delegation - politicians or highlevel officials who determine the extent of discretion available to lower-level officials may be overly risk-averse, to the extent that the electorate is more attentive to corruption scandals rather than an efficient provision of public goods. Such incentives - whether electoral or promotion-related - may then lead to insufficient delegation and discretion.

In this paper, we study both the determinants and consequences of discretion in the context of government procurement in Italy. Procurement accounts for a large fraction of government expenditure worldwide; for example, for OECD countries the procurementto-spending ratio held steady at around 30 percent during 2007-2015 (OECD [2017]). Furthermore, corruption is thought to result in substantial "leakage" from procurement expenditures, even in more developed (and less corrupt) countries. ${ }^{1}$ Thus, understanding how procurement rules might impact corruption is of interest in its own right, in addition to serving as an apt setting for studying the trade-offs associated with discretion in government bureaucracies more generally. ${ }^{2}$

Our work is enabled by the use of a confidential database obtained from the Agenzia Informazioni e Sicurezza Interna (AISI), the Italian equivalent of the FBI. The database lists individuals that have been flagged by the AISI as suspected of various crimes, including corruption. By linking this list to administrative data on the top employees and owners of Italian companies, we classify a firm as investigated for corruption if at least one employee or owner was flagged by the AISI for suspected corruption. We then link the resultant firm-level database to information on over 200,000 procurement auctions for the construction and maintenance of public infrastructure held throughout Italy during 20002016. The data include the near-universe of auctions involving the two most frequently procured types of contracts: those involving either civic buildings or roads, highways, and bridges. These data allow us to observe whether investigated firms participated in or won each auction. Finally, we complement these firm-level data with similar information on

\footnotetext{
${ }^{1} \mathrm{~A}$ study sponsored by the European Commission reports that, in projects that were found to have been corrupted, 13 percent of expenditures were lost due to corruption (Ferwerda and Deleanu [2013]).

${ }^{2}$ Agency problems in procurement extend beyond governments. For example, in a recent working paper, Bergman et al. [2021] documents the adverse consequences of favoritism in hospitals' procurement of medical services.
} 
investigations for corruption charges involving the public officials in charge of awarding (and follow-on monitoring) the contracts in our data (we use the same terminology of "investigated" and "clean," or "non-investigated," that we use for businesses also for the public officials in charge of the auctions). We know of no other database of corruption risk for individuals and organizations that is comparable to ours.

The scale and richness of our data are such that we may employ a range of fixed effects and controls, which helps to rule out a number of alternative interpretations, which inevitably arise in correlational results. For example, in our analyses that look at the characteristics of auctions won by firms under investigation for corruption, we may include over 6,000 procurement authority (PA) fixed effects, so that we identify the relationship based on the selection of different auction mechanisms by the same entity (e.g., a municipality), or PA-year fixed effects so that we identify the relationship based on the selection of different auction mechanisms in the same place during the same year. The latter specification allows us to account for any potential unobserved time-varying shocks at the procurement authority level.

We begin by examining the types of auctions that are most often won by investigated firms. We show that two auction arrangements are significantly more likely to lead to a contract being awarded to an investigated firm: first, so-called scoring rule auctions, which involve (potentially subjective) non-price selection criteria that may restrict competition, are 1 percentage point ( 6 percent) more likely to be won by investigated firms, relative to first-price (non-discretionary) auctions. Auctions that use "negotiated" procedures in which procurement officials invite bidders (rather than allow for open bidding) are no more likely to be won by firms investigated for corruption, relative to open auctions. However, when we look at the subset of negotiated auctions in which officials fail to invite the requisite number of bidders (which we take to be an indication of abuse of discretion), we find a 1.9 percentage point (11 percent) higher probability of an investigated winner. While more at risk of selecting investigated firms, we also find that scoring rule auctions are associated with lower cost overruns and higher award prices, while negotiated procedures are associated with lower delays and higher award prices. In line with evidence provided by Bosio et al. [2022], we interpret these features as an indication of improved contract execution.

We then link the choice of discretionary auctions to the characteristics of procurement administrators that deploy them. In particular, we look at whether the choice of discretion is affected by whether the auction was administered by an individual that the AISI has flagged as suspected of corruption, and also whether the auction occurred in a municipality in which the AISI has identified at least one such official. The first of these analyses aims to examine whether individual procurement officials prone to corruption are 
more likely to select (corruptible) discretionary auctions; the second examines whether locales where suspected corruption is present tend to use "corruptible" discretionary auctions. Our results show effects that go in opposite directions: public officials suspected of corruption are 2.9 percentage points more likely to use one of the two discretionary auction types we flag for concern (discretionary criteria or discretionary procedures with too few invited participants). By contrast, discretionary auctions are 1.9 percentage points less common in "corruption-suspected" municipalities.

We describe how our results may fit with an intuitive explanation based on classic models of delegation put forward by Holmstrom et al. [1982] and applied to the bureaucratic delegation problem by Epstein and O'halloran [1994]. In our context, greater discretion allows for more efficient implementation of government projects by well-informed and well-intentioned procurement officials, which must be traded off against the higher probability of leakage by corrupt officials. If the choice of auction design is one of the primary means of oversight by a (non-corrupt) central monitor, then less discretion will be allowed in locales where the probability of corruption is higher. When possible, however, corrupt officials deploy discretion, to the benefit of corrupt firms.

Overall, the empirical findings in this study offer a new, detailed assessment of the extent of - and the mechanisms involved in - corruption in infrastructure procurement. On the fundamental question of whether a central legislature or senior bureaucrat chooses to impose excessively strict constraints on lower-level officials, while our analyses do not allow for decisive welfare calculations, we argue that the data provide suggestive evidence of overly strict constraints. This argument is exemplified by the consequences of a mid-2000s reform in which the Italian legislature loosened regulations governing the use of negotiated procedures. Whereas such contracts could only be deployed for relatively small projects (under $€ 300,000$ ) in the early 2000s, by 2011 the limit had been raised to $€ 1,000,000$. This change, motivated by the government's desire to stimulate the economy by reducing the procedural times to award public contracts, led to a massive increase in the share of auctions held via negotiated procedures, from 10 percent in 2006 to 60 percent by 2012. Yet the vast majority of these (83 percent) were conducted using mechanisms that preserved supplier competition (i.e., with the legally required number of bidders), and hence the loosening of rules had at most a very small effect on the fraction of contracts awarded to firms under investigation for corruption. And in locations in which officials might have exploited discretion, their use was relatively limited. Indeed, calculations based on our estimates imply a 0.05 percent increase in investigated winners overall between the periods before and after the increase of the threshold for using negotiated procedures. This appears to be a small cost when compared to improvements in contracting quality from discretion, such as a 14 percent reduction in delays. 
Thus, the primary implication of our analysis is that supplier competition may play a central role in curtailing the corruption risk that may accompany greater buyer discretion.

\section{Literature}

Our paper sits at the intersection of several distinct literatures, and we organize our discussion of this related work around what we see as our five main contributions.

Taken as a whole, our results suggest that greater discretion had only a limited impact on corruption (but did reduce delays, and plausibly also costs). This first contribution is relevant to our understanding of the efficiency-corruption trade-off in delegation. The seminal study of Banfield [1975] observed that reducing discretion may limit corruption, albeit at the expense of constraining honest public officials from exercising their judgment to the benefit of public welfare. This links to the rich and extensive literature on government decentralization and delegation. Huber and Shipan [2006] and Bendor et al. [2001] provide earlier overviews of this body of research; we see our work as corresponding to their models of "ex-ante constraints" (as in the reduced use of discretion that we study here) rather than ex-post monitoring. More closely related, Bosio et al. [2022] shows, using cross-country data, that constraints on discretion are associated with better procurement outcomes, but only in countries with low public sector capacity. ${ }^{3}$

Our second contribution is a new measurement of corruption in public contracts that is plausibly more credible and more accurate than prior measures. There is a vast and growing body of work on the political and economic analysis of corruption (see Olken and Pande [2012] and Burguet et al. [2016] for recent surveys of corruption that review and synthesize various models of delegation), which reflects the potential importance of corruption to the functioning of government, and the correspondingly substantial resources devoted to fighting corruption. Thus, we see it as a useful contribution to be able to quantify that 17 percent of public works in Italy are awarded to investigated firms. ${ }^{4}$ Our third

\footnotetext{
${ }^{3}$ Related work by Bandiera et al. [2020] investigates delegation in public procurement by experimentally varying the amount of autonomy granted to procurement officers. They find that shifting decision-making rights from monitors to officers reduces procurement prices. While our analysis also indicates that discretion improves procurement outcomes, our study focuses on a different type of channel (the choice of award procedures and criteria) and a different outcome (the risk of selecting criminal contractors). Similarly, two studies concurrent with our own provide evidence that the expanded use of discretion can improve [Carril, 2019] or worsen citepszucs2018 procurement outcomes. These studies document significant bunching of contracting activities below the discretionary threshold, suggesting a role for buyers manipulation, while we do not detect any such distortions. More broadly, given the monitoring function of higher-level governments, our findings also relate to the literature on the costs and benefits of decentralization (e.g., Bardhan and Mookherjee 2006).

${ }^{4}$ Our work also relates to studies linking procurement to firm political connections, although our measure of corruption risk is clearly distinct. Mironov and Zhuravskaya [2016] document how firms with public procurement revenue increase the tunneling of funds to politicians around elections. They
} 
contribution concerns the strengths and weaknesses of different procurement methods to limit corruption risks. Our finding that discretion has limited impact overall on corruption is in line with Bandiera et al. [2009], who analyze centralized versus decentralized public procurement and show that excessive payments for standardized goods are driven more by inefficiency than corruption. ${ }^{5}$ Our results provide evidence on a well-defined source of inefficiency, namely excessively rigid contracting procedures. Several other studies link procurement methods and oversight to project outcomes. Notable contributions include Brierley [2020], who shows that greater oversight may backfire if politicians themselves are corrupted (a result in the spirit of the classic study of hierarchical corruption in Indian canals by Wade [1982]), Lewis-Faupel et al. [2016], who document the positive impact of e-procurement on road quality in India and on execution time Indonesia, possibly by limiting interactions with corrupt public officials, and Djankov et al. [2017], who document the correlation across countries in procurement rules and practices and link these to survey-based measures of road quality. The central role of competition in curtailing corruption that we uncover parallels the recent work of Colonnelli and Prem [2017], which also points to the role of limited competition in creating rent-seeking behavior in Brazilian procurement. At the macroeconomic level, these are key results for the larger objective of assessing the quality of fiscal policy, as underscored by the recent interest in opening up the black box of "Big G" [Cox et al., 2020].

The fourth contribution relates to the heterogeneous impact of procurement rules across different public organizations. In particular, we show that discretionary auctions are relatively rare in high-corruption areas, but are commonly deployed by individual administrators under investigation for corruption. While these two findings are, at least superficially, in tension with one another, as we discuss below they follow from a simple model that is very much in line with standard theories of delegation.

Overall, our results indicate that governments are aware of the trade-off created by discretion, and take it into account in the extent to which it is allowed in different areas. This latter finding was suggested by Coppier et al. [2013], who noted that there is greater discretion in (low-corruption) U.S. and U.K. procurement. Coviello et al. [2017], in their investigation of the economic impacts of allowing greater discretion in the public

also document that more corrupt locales tend to award contracts to less productive firms. Auriol et al. [2016] show that politically connected companies are more likely to win auctions with limited competition, which they take to be an indication of corruption. A similar approach is taken by Baltrunaite et al. [2018] in the setting of Italian auctions, in linking political connections to discretionary auctions. Brogaard et al. [2016] show that contracts won by politically connected firms in the U.S. tend to have poorer performance. Our work is distinct from these earlier efforts in a number of ways. Most importantly, we have an unusual country-wide measure that allows us to identify firms as potentially corrupt.

${ }^{5}$ Along similar lines, several recent studies have shown that limiting the discretion of procurement officials is most valuable when the skills or abilities of the public buyers are lower; see Best et al. [2019], Bucciol et al. [2020] and Decarolis et al. [2020]. 
procurement of works in Italy, also notice that higher-corruption provinces tend to use less discretionary auction procedures. We are, to our knowledge, the first to identify this relationship systematically based on local variation in corruption.

Our fifth and final contribution is to the debate on anti-corruption policies in public procurement. While there is much theoretical work in this area (see, e.g., Ortner and Chassang [2018], for one recent contribution), there are scant empirical findings. The few exceptions include Olken [2007], which provides a comparative analysis of centralized audits versus grassroots participation in monitoring; Di Tella and Schargrodsky [2003], which presents evidence on the combined effect of public officials' wages and corruption audits; and Avis et al. [2018], which provides causal estimates of the effects of past anti-corruption audits on subsequent corruption levels. Our findings on the role of firm competition to limit the corruption risk of discretionary auction procedures and criteria are relevant for this policy-relevant research agenda. We return to policy considerations in our conclusion.

\section{Background and data collection}

\section{III.A Institutional details on Italian procurement}

In recent years, Italian regulations that govern public procurement underwent a number of reforms as a result of, among other things, the passage of European Union Procurement Directives aimed at creating a common set of rules for public procurement in the EU. In particular, these reforms aimed to improve the design of source selection systems, i.e., the process for evaluating bids. We study public contracts under the "ordinary

regime," which sets the procurement rules for most projects, excluding secret military contracts and some strategic infrastructure projects.

Source selection systems under the ordinary regime vary along two main dimensions: the awarding procedure and the selection criterion. Starting with the first dimension, there are two primary procedures for awarding contracts: open auctions and negotiations. Open auctions are "ordinary" procedures for the assignment of procurement contracts in which all firms eligible to execute public contracts can bid. In these procedures, the contracting officer overseeing the project has little discretion in the choice of contractor. These auctions presume the feasibility of accurately defining, from the outset, the relevant scope and technical specifications of the contract.

Negotiated procedures are, by contrast, marked by significant discretionary powers. The contracting officer consults a set of prospective contractors and may negotiate the conditions of the contract with one or more of them. Given their discretionary nature, 
negotiated procedures are treated as exceptional, and admissible only under specific conditions: for the most part, they are permitted only for contracts below a given monetary threshold. Above this threshold, negotiations are allowed only when there is some urgency in fulfilling the contract, or when a previous attempt to run an open auction failed to elicit any bids.

The second key aspect of contracting is the specification of the criterion for determining the winner. Both open and negotiated procedures can use either the "lowest price" criterion or a "scoring rule" criterion (also known as the "most economically advantageous tender" criterion). In the first case, the enterprise offering the lowest price is awarded the contract, provided that this offer is judged to be reliable, that is, the offer is not so low as to be unrealistic. The second approach allows for the accounting of a broader range of considerations beyond price, as specified in the call for tender. Non-price parameters of a bid may include both hard and soft elements. An example of a quantitative (hard) parameter could be the number of engineers that will work on the specific project, while an example of a soft element is the aesthetic quality of the proposed solution. There are a few limits that regulations place on the choice of parameters. In particular, criteria must all pertain to the bid and not the firm, so that past performance cannot be used as a parameter. But procurement officials enjoy wide margins of discretion in setting the parameters (possibly to the advantage of specific firms) and their associated weights. ${ }^{6}$ The inclusion of multiple parameters can be used to restrict competition, to the extent that only a narrow set of firms may be able or willing to participate in the 'restricted' auction. Indeed, our data confirm a lower level of competition in scoring rule auctions see Figure A3. ${ }^{7}$

As one might expect, the full set of regulations governing procurement is far more complex than we can describe here, and we defer to Decarolis and Giorgiantonio [2015] for a more in-depth discussion. However, we observe that, beyond some modest differences, the set of procedures and criteria governing Italian procurement are quite general, allowing only for limited regional variation. This is important, in particular, as it is difficult for individual regions to create rules that favor local firms, which would present a confound for our analysis. Indeed, given the constraints laid down by the European Union, Italian procurement rules also characterize the institutional framework in the EU more

\footnotetext{
${ }^{6}$ An illustrative example may help convey this point. In 2007, the Italian Supreme Court confirmed the conviction of a group of public officers and business owners for rigging multiple scoring rule auctions in the Santa Maria Capua Vetere municipality. The scheme involved public officials drafting calls for tenders following the recommendations of favored firms: parameters in the scoring formula emphasized elements that advantaged pre-identified firms, e.g., by specifying the use of a specific brand of machinery.

${ }^{7}$ The extensive use of scoring rules in favoring bribe-paying firms has been well-documented by Campos et al. [2021], in their analysis of the massive corruption case involving Brazilian multinational Odebrecht.
} 
generally. But they also reflect procurement rules in a much broader set of countries, as documented in a recent survey by the World Bank [2017].

One particular feature of procurement rules does warrant further elaboration, given our focus on delegation and discretion by individual procurement officials. Whenever not expressly constrained by national or local rules, the choice of both the awarding procedure and the selection criterion is delegated to the contracting officer overseeing each contract (the "Responsabile Unico del Procedimento", or RUP). This public official is selected from among management-level bureaucrats in the relevant public administration (PA), unless none is available for this role (in which case special rules apply). The RUP is nominated via a formal act by the PA's top official, which in municipalities is the mayor.

The RUP is in charge of managing the entire contracting process, from the project definition phase, through the bidding phase, to the awarding and realization of the contract. Thus, the RUP has considerable control over how the contract is structured. But this discretion has to be exercised within the regulatory constraints imposed by European, national, and local regulations, and it is subject to oversight both internally within the PA, and from third-party auditors (at the local, national and, in certain cases, European level; see Figure A1). A RUP who wishes to use a discretionary procedure or criterion may aim to be appointed to oversee auctions that are amenable to such methods, and conditional on the project may select more discretionary approaches. However, it is difficult to make strong inferences about a RUP's intent merely from the selection of discretionary auctions. A socially-motivated procurement official may also choose a negotiated procedure to expedite project execution and (with the interests of the municipality at heart) even manipulate contract amounts to facilitate their use. We thus rely on detailed data on RUP and firms described below to discern whether discretion is more plausibly used for self-serving reasons.

\section{III.B Data}

\section{III.B.1 Procurement Data}

Our procurement data come from a database provided by the Public Contracts Observatory at the Italian Anticorruption Authority (ANAC), the public entity that oversees public procurement in Italy. Since 2000, ANAC has monitored all public contracts above the threshold reserve price of at least $€ 150,000$ until 2010 , and $€ 40,000$ thereafter.

Our dataset contains the universe of ANAC data for the years 2000-2016 for public infrastructure. ${ }^{8}$ Amongst these, those involving civic buildings (OG01), or transporta-

\footnotetext{
${ }^{8}$ Italian procurement more broadly can be divided into three categories: works, goods, and services. Our focus is on public works, which represent around $25 \%$ of the value and over $30 \%$ of the total
} 
tion infrastructure such as roads, highways, and bridges (OG03), are the most relevant categories which, combined together, represent more than half of all contracts, both in terms of number of contracts as well as money spent. ${ }^{9}$ For each contract, we have detailed information about the contracting phase, including the start and end date of the bidding process, the type of contracting authority, the auction procedure used to award the contract, the selection criterion, the number of bidders, and the identity of the winning bidder. The data also include information on auction outcomes, such as the initial project value, the winning discount and total effective costs, the expected and effective contract duration and, for auctions held after 2010, we observe all of the bids.

We observe 5 types of contracting authorities in the data: central administrations, municipalities, other local administrations (regions and provinces), state-owned enterprises, and "decentralized administrations" (specifically, hospitals and universities). For each authority, we know the identity of the RUP managing each contract, and for most contracts we also know the exact geographic location (the exceptions include central government administrations, decentralized regional administrations (such as hospitals and universities), and also highways and railways that span geographic boundaries). Local institutions - municipalities in particular - play the largest role in public works procurement. Local governments account for $72 \%$ of total projects awarded (53\% municipal councils, $14 \%$ provincial councils, $3 \%$ regional governments). While about half of the contracts in our database are awarded by municipal councils, they are relatively small projects, with an average value of $€ 527,000$, as compared to an average value of $€ 847,000$ for provincial and regional governments, and over $€ 1.5$ million for hospitals and universities. There is also a wide range in the number of contracts per contracting authority. There are 1,266 municipal councils that awarded only a single contract (mean population of 1,404$)$, whereas the municipality of Rome alone awarded 3,519 contracts.

As previously noted, the contracting authority can choose between two main types of awarding procedures, open and negotiated. If the latter is selected, we additionally observe the number of firms invited to participate in the auction, and for all auctions, we see the number of firms that present offers (the number of bidding firms is, by definition, less than or equal to the number of invited offers). Furthermore, we observe the identity of the winning firm and, for auctions held after 2010, also the identities of

number of procurement contracts in Italy. As noted below, the average contract size is around $€ 985,000$, larger than the average size for goods contracts but almost half of the average size for service contracts. Consistent with the size difference, negotiated procedures are used significantly more frequently for public works (they represent around $72 \%$ of the total) than in the procurement of services, where they are used in only $60 \%$ of contracts.

${ }^{9}$ The procurement of public infrastructure is subdivided by law into 13 job types (OG01,.., OG13). Although the data contain codes that refer to more detailed sub-categories, OG codes are more reliable since this latter classification is the only one required by law. 
all participants. Under normal circumstances, negotiated procedures require a minimum number of invitations. When we observe fewer than the legally mandated number of invitations, we flag the auction as involving potential abuse of discretionary procedures (denoted by the variable DiscretProc lowN $_{\text {) }}$. Conversely, we denote as DiscretProc highN $_{\text {. }}$ negotiated auctions with the legally mandated number of bidders. Finally, we denote all negotiated procedures (both highN and low $N$ ) by the variable DiscretProc. Note that a below-minimum number of invited bidders does not automatically indicate abuse - it may instead result from a contract's urgency or a lack of qualified firms. ${ }^{10}$

Auctions may be awarded based on a price-only system or one that incorporates a wider set of considerations (i.e., scoring rule auctions). ${ }^{11}$ Since scoring rule auctions allow for a range of non-price (and potentially subjective) parameters set by the RUP and thus involve more discretion than first-price auctions, we define an auction as having a discretionary criterion (denoted by the variable DiscretCrit) if it is awarded via a scoring rule.

To capture the two types of discretionary auctions we will emphasize, we define a summary measure, Discretion, which denotes auctions for which DiscretProclown $=1$

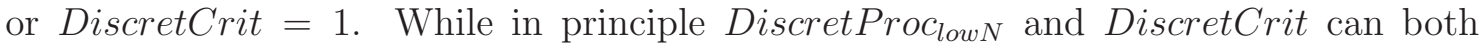
occur simultaneously, this is rarely the case in practice since the regulations tend to favor negotiations for smaller value (or urgent) contracts, while the scoring rule system is used for complex projects and requires more time to award the contract since a commission, and not just the RUP, evaluates the bids.

Beyond our measures of auction procedure and criterion, we include a number of other auction attributes as controls. Most importantly, we control for the auction reserve price (Reserve), which is the monetary value, reported in the call for tenders, above which the PA is unwilling to pay for the contract. Price bids are expressed as discounts over this reserve price. In our analysis, the reserve price will enter linearly (in logarithm) as a control in many of our specifications, as well as via a series of dummy variables for contracts in various reserve price ranges, which correspond to thresholds that triggered stricter rules and/or monitoring of an auction, with cutoffs of $€ 100,000$; 150,000; 300,000; 500,000; 1,000,000, and 1,500,000. At these threshold values, both the publicity requirements of the call for tenders and the set of eligible bidders change.

The auction database provides us with additional information that we will exploit

\footnotetext{
${ }^{10}$ To the extent that this is the case, the link between discretion and corruption will be underestimated.

${ }^{11} \mathrm{~A}$ third alternative is also available, the so-called average bid auction (ABA). The ABA is a variant of the first-price auction in which the winner is the firm offering the lowest price among a subset of "nonexcluded" offers. The ABA induces higher participation as well as bid coordination (Decarolis [2018], Conley and Decarolis [2016]), but for our analysis, we simply view it as a non-discretionary auction. Hence, we will not treat it separately from the other first-price auctions.
} 
in the analysis. In particular, we observe the identity of the firm winning the auction. Information on each firm includes its name and the location where it was incorporated, as well as a unique social security identifier, which provides the link to the criminal investigations data. Finally, we also observe some standard procurement auction outcomes, including delivery time, price and - for about half of our sample of auctions ${ }^{12}$ - the total costs for completion. Data on the expected contractual duration as well as the effective total completion time allow us to construct a measure of contractual delay (Delay) and cost overrun (Extra Cost). Since Delay can be positive or negative and has extreme outliers, we use an inverse hyperbolic sine transformation. The final price of the winning bid is expressed as a discount over the reserve price (Discount) and, similarly, Extra Cost is calculated as the difference between the final price and the awarding price, over the initial reserve price.

\section{III.B.2 Criminal Investigations Data}

A contribution of this study is to introduce a new measure of criminality in public procurement. As previously noted, in the procurement data we observe bidders' identities. For each firm, we then obtained the full list of its owners and top managers through the Company Accounts Data System. This is a proprietary database maintained by CERVED Group that we observe for four separate years: 2006, 2011, 2014, and 2016. ${ }^{13}$ For each firm, the union of all owners and managers recorded in any of these four periods represents the set of individuals connected to the firm in our analysis. For each individual, their record of criminal investigations (which we will describe shortly) was coded, and this information was aggregated across firm-linked individuals to obtain a firm-level measure of potential criminal status. We use the same criminal investigations database to determine the suspected criminality of each RUP in our data.

Records of individuals' criminal investigations were analyzed for us by AISI (Italy's internal intelligence and security agency) using a centralized archive, the Sistema D'Indagine Interforze (SDI), which is a primary source of information that police officers and intelligence agencies use to identify potential targets for further investigation. ${ }^{14}$ This database contains reports of all individuals investigated by any of the Italian police forces: state police (Polizia di Stato), finance police (Guardia di Finanza), military police (Carabinieri),

\footnotetext{
${ }^{12}$ For a detailed discussion of the reasons behind limited data availability, see Decarolis and Palumbo [2015].

${ }^{13}$ In Online Appendix B, we describe in greater detail how we obtained each of the data sources we employ. We note that most of our data are proprietary so that, while we can provide contact information for interested researchers, we cannot provide the data itself.

${ }^{14}$ The SDI data have been previously used in research by Pinotti [2017]. Our access to the data is enabled via a framework agreement between AISI and Bocconi University.
} 
and environmental police (Guardia Forestale).

An entry in the SDI database typically occurs after a police force, based on a preliminary investigation, determines that there is sufficient evidence to open a formal investigation. This investigation might or might not lead to a court case and, if so, to a conviction. Therefore, court cases are clearly a subset of the entries in the SDI database (see Figure A2). The resulting sample of suspect offenders thus includes individuals that were convicted, acquitted, or never charged. The latter two groups plausibly comprise a large number of offenders whose guilt could not be proven in court. Indeed, corruption cases are generally complex, and convictions are relatively rare. This is particularly true in Italy, where the trial must go through three levels of judgment (Primo grado, Appello, and Cassazione) within a relatively short statute of limitation - between 6 and 12 years. For example, in the well-known "clean-hands" case, out of the 2,565 people investigated for corruption, 1,408 were convicted, 544 were acquitted for lack of conclusive evidence, and 488 due to the statute of limitations Davigo and Mannozzi [2007]. For these various reasons, official data on (convicted) offenders may greatly understate the extent of corruption. $^{15}$

Although the SDI data do not suffer to the same extent from the under-reporting problem that afflicts judicial data, they may instead include false positives. While in general one may be concerned that investigations overstate the extent of underlying crimes, there are features of corruption and also our specific context that make this less likely to occur. Because the credibility of these data is central to our empirical exercise, we now explain these reasons in some detail.

We begin by noting that participants in procurement corruption in particular are all likely to benefit to some extent, with the costs borne by society. Hence, in contrast with many other types of crimes in which a victim is directly involved-and motivated to inform investigators-this is less likely to be the case for corruption. Indeed, as discussed earlier, investigations are often initiated based on information that enforcement authorities receive from competitors of firms engaged in corruption.

In the specific context of our study, several features further reinforce a tight connection between investigations and the underlying crimes. Understanding why this is the case requires an elaboration of what Italian law defines as corruption crimes. There are two main articles in the Italian penal code devoted to corruption. The first is Article 318, which states that any public official who, in conducting their duties, receives money or other benefits for himself or for a third party (or accepts a promise of future benefits), is

\footnotetext{
${ }^{15}$ Decarolis and Giorgiantonio [2019] analyze the universe of court sentences for corruption in public auctions finding that only $2 \%$ of the firms awarded public contracts were thus implicated. In the same set of auctions, our measure flags $17 \%$ of contract winners as potentially criminal (note that Decarolis and Giorgiantonio [2019] use a smaller and different set of auctions than the one used in our paper).
} 
to be imprisoned for one to six years. In our context, this might include a procurement official demanding payment from firms to be permitted to bid on a contract - for example, some court records have revealed instances of corrupt officials deliberately creating impediments to firms' ability to conduct the worksite inspections that are compulsory before being eligible to bid in an auction. The second, Article 319, concerns more serious acts of corruption, specifically, the omission or delay of official duties, or performing acts that run contrary to official duties, in exchange for benefits (or promise of benefits) for themselves or a third party (e.g., a procurement official awarding a contract to an underqualified bidder). Such acts are punishable with a six to ten year prison sentence. The law draws a distinction between the less-serious case of "improper corruption" (Art. 318) in which the official receives a benefit to perform duties that are within their purview, as compared to the more serious case of "proper corruption (Art. 319), in which the official acts contrary to his duties. ${ }^{16}$

The two types of corruption have distinct implications for reporting incentives, but we argue in neither case is there an obvious motive for frivolous whistle-blowing. Under proper corruption, a public agent's actions may be revealing of corruption because they violate his official duties, but none of the parties involved has a direct motive to act as an informant. By contrast, under improper corruption, the actions by the public agent are less likely to raise suspicions (since they involve his regular duties); however, the parties involved may be more inclined to inform investigators, given that they are forced to pay for something (like the opportunity to bid on a contract) that they are legally entitled to. Despite this reporting incentive, the best response of involved participants may nonetheless be to remain silent, if there are potential reputational effects that could impact interactions with other officials, and especially if they may interact with the same official again, either over time or across contracts.

Several other features of Italian procurement result in a very high bar for initiating investigations. First, unlike some other countries, Italy has no leniency program to encourage one party to denounce the other. Moreover, according to Article 321 of Italy's penal code, punishments for all implicated parties are symmetric-e.g., a bribe-payer faces the same penalty as the recipient. This inability to secure lenient treatment reduces reporting incentives. ${ }^{17}$ Second, detecting procurement corruption in Italy is widely considered to be

\footnotetext{
${ }^{16}$ As we explain later, we also include in our measure two other types of crimes which, broadly speaking, represent forms of corruption, but for which the Italian law uses ad hoc definitions - ("peculato" and "concussione"). Such crimes are less prevalent than those falling under the definitions of articles 318 and 319: for instance, in 2016 there were 126 individuals imprisoned for corruption (under Articles 318 and 319), 26 for "peculato", and 11 for "concussione."

${ }^{17}$ Reforms to encourage better local governance and whistleblowers to come forward have proven ineffective. The governance changes require that each PA (municipality etc.) nominate an official to be responsible for anti-corruption and that each PA provides an annual anti-corruption plan. In practice, few
} 
harder during our sample period, as a result of the "mani pulite" (clean hands) scandal of the 1990s. In the period before this scandal, corruption in public contracts was systematic and served as an unofficial means of financing national political parties' election campaigns. This systematic corruption was disrupted by the "mani pulite" revelations, and as a result bribery in procurement became a more localized phenomenon, based on a plethora of small-scale partnerships between individual public officials and firms. To the extent that it is more difficult for police to detect smaller, localized cases of corruption, this development further reduces the problem of over-reporting in our data. ${ }^{18}$ Finally, it is extremely difficult to collect evidence to initiate a corruption investigation because of, for example, limits on police powers to monitor the communications of suspected parties; the police may only do so if there is clear evidence from the outset of "major guilt." As a result, among cases reported to the police, there will rarely be sufficient evidence even to open a case and thus appear in our data. ${ }^{19}$

We suggest that the preceding arguments indicate that our investigations-based measure is unlikely to be overly afflicted by false positives. However, we argue that any measure based on court convictions would be plagued by an excess of false negatives. There are two main reasons for this. First, particularly in Italy, the burden of proof for corruption convictions is very high, requiring that the plaintiff show convincing evidence of: i) the benefit directly (or indirectly) given (or promised) by the public official to a counterpart, ii) the delivery by the counterpart of money or other benefits to the public official (or to a person or entity connected to them), and iii) the link between these two actions. There are numerous factors that make it difficult to meet this bar. For example, there is a significant time lag between the benefit received by a firm (say, the awarding of a public contract) and any payback. Moreover, the latter is often hard to detect and prove as it could involve indirect forms of benefit, such as the hiring as consultants or subcontractors of persons linked to the public official (family members, friends or figureheads). ${ }^{20}$ The high burden of the proof, coupled with the limitations on evidence

PAs have adopted effective programs. The new whistleblower law does not guarantee the full anonymity of the whistleblower, a serious limitation in encouraging anyone to come forward to report corruption.

${ }^{18} \mathrm{An}$ example of this evolution in the nature of public contract corruption comes from the President of the Italian Antitrust Authority: "[Whereas corruption in] the First Republic was elevated to a "system," today micro-corruption prevails, and perhaps for this reason appears more pervasive. I don't share the view that "the thieves have won" nor that today is worse than then. The numbers prove it. The Enimont Affair, which was called "the mother of all bribes," involved around 140 billion lire. For cases today, as anyone can verify on the Istat website, we are talking about 120 million. The bribes paid to carry out the Mose, one of the biggest scandals of recent years, amounted to a few million Euros." See https://luz.it/en/spns_article/intervista-cantone-corruzione/.

${ }^{19}$ For this reason some policymakers have in recent years proposed extending to corruption crimes the same powers of investigation that the police have for mafia-related crimes, see https://formiche.net/ 2016/10/libro-corradino/.

${ }^{20}$ Corruption experts often raise the related concern that under Italian law the presence of an inter- 
collection described earlier, makes it particularly challenging to prosecute Italian corruption cases. Given these challenges, it is perhaps unsurprising that any investigations that are opened proceed very slowly, often lasting for many years. ${ }^{21}$ This leads to a further reason why there are so few corruption convictions: Italy's relatively short statute of limitations. If an investigation is still ongoing as the statute of limitations approaches, the plaintiff must decide whether to go to court or simply dismiss the case. In the latter case, there is of course no conviction; in the former, a rushed case will likely be weak and a conviction unlikely, and very likely accounts for the relatively high rate of acquittals for corruption cases. $^{22}$

In concluding our discussion of the investigation data, we note that the investigated individuals are unaware that they are under investigation, unless the case is formally brought to a criminal court. For the same reason, unless a formal court case has begun, a PA cannot exclude firms from auctions even if their owners/managers are investigated for corruption charges.

To obtain these data for firms, AISI searched the SDI database for all managers and owners we identified as associated with each firm, and flagged those who had been investigated for corruption and other related crimes. Specifically, the following categories of crime were considered: corruption, malfeasance, and embezzlement; abuse of power and undue influence; and violations in public auctions. Based on the individual-level records extracted from SDI, suspected criminals in 3,848 firms winning a contract over

mediary between the public official and the entity benefiting from its acts creates a further complication in proving corruption, as relations among the various parties to this type of multi-layered structure need to be proved. Hence, even direct proof of a payment to a public agent by an intermediary is insufficient as evidence of corruption unless it can also be proved that such payment can be related to an action taken by the public agent to favor a business on whose behalf the intermediary made the payment. This is in contrast, for instance, to what is required under the 1977 U.S. Foreign Corrupt Practices Act which states: "It shall be unlawful (...) to make () offer, payment, promise to pay, or authorization of the payment of any money, or offer, gift, promise to give, or authorization of the giving of anything of value to any person, while knowing that all or a portion of such money or thing of value will be offered, given, or promised, directly or indirectly, to any foreign official." Under the latter piece of legislation, it is thus very clear that it is unlawful to make any payment that has the potential to be used in full, or in part, as a bribe to a public official. This is a substantially more attainable burden of proof than that required under Italian law. For a discussion of this issue and its application to the court acquittal of the top management of the Italian oil company ENI in an alleged corruption scandal, see https: //www.giurisprudenzapenale.com/wp-content/uploads/2020/05/Scollo_gp_2020-5.pdf, last accessed February 5, 2023.

${ }^{21}$ See, e.g., https://www.dirittoconsenso.it/2021/06/25/la-durata-delle-indagini-preliminari/, last accessed February 5, 2023.

${ }^{22}$ The media often blames the statute of limitations for the lack of corruption convictions; see, e.g., https://www.lastampa.it/cronaca/2016/01/27/news/ italia-ancora-bocciata-per-corruzione-ma-i-condannati-in-carcere-sono-appena-126-1.

36555629/, last accessed February 5, 2023. As one particularly prominent example, out of the 36 court cases in which Silvio Berlusconi has been accused of some crime, three involved corruption charges and, out of these three, one is still ongoing and two ended due to the statute of limitations. 
the period 2000-2016 were identified (9.8\% of all firms winning at least one contract). We define InvestigatedWinner as an indicator variable denoting that an auction was won by a firm ever associated throughout our sample period (via employment or ownership) with at least one individual present in the SDI database. Under our agreement with AISI, we were unable to obtain year-specific information on whether an investigated individual was associated with a given firm - our measure thus varies only across firms and not over time. This approach is conservative, as the date at which suspect offenders are reported in the SDI provides little information - if any - on the date an offense was actually committed.

The SDI data also allow us to flag procuring agencies and public administrators as suspected of corruption. For each auction, we observe the agency procuring the contract and, within the administration, the RUP in charge of the specific contract. AISI searched the SDI database for all RUPs, flagging those suspected of the same types of crimes used to flag managers and owners (i.e., corruption, abuse of power, and so forth). Overall, $6 \%$ of the RUPs in our sample (managing $9.7 \%$ of all contracts) were flagged as "investigated." We use this list to identify auctions administered by an investigated RUP (InvestigatedRUP) and also administrations in which at least one investigated RUP was employed during our sample period (16\% of all public administrations, denoted by InvestigatedPA, managing $40 \%$ of the contracts).

In concluding our discussion of the criminality data, it is important to discuss two, related potential problems: reverse causality and sorting. In our setting, reverse causality could occur if, for instance, a firm would become more likely to be labeled as a suspect when winning negotiated procedures (with few participants) due to the police concentrating its (limited) monitoring efforts on these types of procedures. We believe that, if anything, the opposite is in fact likely to be true in our data, based on extensive discussions with the AISI representatives who helped us in accessing the police data. These officials gave no indication that police monitoring efforts are concentrated on public tenders characterized by the criteria and procedures analyzed in this study. Furthermore, they emphasized that investigations typically result from complaints to the police from a losing bidder, which are less likely for negotiated procedures, for two reasons. First, there are simply fewer firms in negotiated procedures. Second, since procurement officers open themselves up to scrutiny when bidders complain, it is also reasonable to assume that officials will use their discretion in negotiated procedures to avoid inviting firms which, for any reason, are more likely to report concerns to the police (this is even more the case if the public official is himself corrupt and has a favored firm among the participants). Thus, while we cannot rule out reverse causation entirely, we believe that if a differential monitoring intensity between negotiated and open procedures is present, in our context it would most plausibly imply that the estimates we present below represent a conser- 
vative assessment of the increased corruption risks associated with reduced competition and discretion. ${ }^{23}$

Finally, on the issue of sorting, it could involve both suppliers and contracting officers. For firm sorting, one might worry that firms that expect to be awarded contracts through discretionary systems might exert additional effort to avoid being detected as potentially corrupt. Such efforts might include using figureheads as company owners and managers. ${ }^{24}$ However, as mentioned above, it is not the case that certain types of procurements are more systematically investigated than others by law enforcement agencies. Since the controls placed on firms are lower for smaller contract values, we should expect a greater presence of investigated firms participating in and winning lower-valued procurements. However, since lower-value contracts are also those for which discretionary procedure auctions can be used, this could mechanically lead to us to find a positive association between discretion on corruption. Similarly, an obvious concern about contracting officers is whether the RUP might manipulate the contract value to make it eligible for the use of discretionary procedures. Such behavior is illegal, as it is expressly forbidden by procurement law. A corrupt RUP might nevertheless choose to take this risk if discretionary procedures were instrumental for rent-seeking activities. In this case, the presence of manipulation should, if anything, increase the probability of detecting an effect of discretion on corruption, assuming that bureaucrats who sort below the threshold are using this leeway to benefit investigated firms. Overall, it is very unlikely that sorting by either suppliers or contracting officers can explain why our estimates below show that discretion does not lead to more corruption.

\section{III.B.3 Descriptive Evidence}

We begin by presenting an overview of some of the main features of the data. While in our main analysis we exploit within-municipality variation over time or (in some cases) within-region variation across municipalities, the patterns in this subsection explore trends across time and broad regional differences in procurement practices at a relatively high level of aggregation.

One important feature of our institutional setting is that the maximum reserve price for negotiated contracts was increased from $€ 100,000$ to $€ 500,000$ in 2008 , and then to

\footnotetext{
${ }^{23}$ However, one important observation from the AISI is that monitoring efforts are concentrated in geographical areas where the presence of criminal organizations has been previously detected, and as a result we will need to take care in interpreting results involving variation at the municipality level in the presence of investigated firms. (Though to the extent that these factors are time-invariant, our fixed effects specifications account for these geographic factors.)

${ }^{24}$ This behavior is found by Daniele and Dipoppa [2019] in the context of firm subsidy allocation in Italy. The extent of likely figureheads is substantially larger for firms obtaining subsidies below the threshold value that triggers the need for special certifications on probity of the owners and managers.
} 
$€ 1$ million in 2011. As we show in Figure 1, this led to an increase in negotiated contracts; the fraction of contracts awarded via scoring rule (the complement of first-price auctions) remains roughly constant.

Did this change result in more contracts awarded to investigated firms? In Figure 2, we examine whether there is any obvious evidence in favor of this view in the aggregate data. The figure plots the fraction of contracts won by investigated firms for three groups, based on the relevant thresholds for the 2008 and 2011 expansions: contracts less than or equal to $€ 500,000$, those between 500,000 and 1 million, and contracts above 1 million. If discretion led to greater corruption, we would expect a relative increase in the fraction of contracts won by investigated firms in the $€ 150,000$ to 500, 000 range in 2008 and 500, 000 to 1 million range in $2011 .{ }^{25}$ However, we observe no discernible change in any reserve price interval after either reform (see Appendix Figure A4). Given that the contract size is endogenous - we observe sorting around each of the thresholds in every year in our sample - it is not possible to provide a sharp interpretation of this "non-result." But at the same time, it does fit with our overall set of findings that we document in the remainder of the paper - discretion in itself does not necessarily promote corruption, and monitors may take steps to ensure that its use is limited in locales in which discretion is mostly likely to be abused.

To provide a preview of why greater discretion might not have increased corruption, we consider two further cuts of the data. First, instead of comparing the fraction of investigated winners by the contract reserve price (as in Figure 2), we present in Figure 3 the fraction of investigated winners for three types of more discretionary auctions: those with negotiated procedures and the legally mandated number of invited bidders (DiscretProc highN $_{\text {) }}$; those with negotiated procedures and "too few" invited bidders (DiscretProc lowN $_{\text {) }}$; and scoring rule auctions (DiscretCrit). Over the full sample period, we observe that negotiated procedures are only associated with criminal winners for auctions when there are fewer than the legally mandated number of bidders. Scoring rule auctions (which have potentially discretionary selection criteria) have the highest rate of investigated winners. Combining these patterns with the general prevalence of each type of auction, one may see why the increased use of negotiated procedures had no discernible impact on the rate of investigated winners - as can be seen in Figure 4, the increase came primarily from auctions that preserve competition, i.e., those with the legally mandated number of invited bidders, a category for which we see a relatively low

\footnotetext{
${ }^{25}$ Note that these reforms were not associated with any other substantial changes concerning bureaucrats' discretion as, for instance, the 2011 reform came about not as an organic reform of the procurement code generally, but as a targeted measure of the Berlusconi government to promote economic growth by expanding the use of the less bureaucratic-intensive negotiated procedures. See Art. 4, sub. r, Law Decree 70/2011, modifying Art. 122, sub. 7, Legislative Decree 163/2006.
} 
rate of corruption. Naturally, in comparing the corruption of different auction types, we wish to control for a range of municipality and auction attributes in comparing various types of auction mechanisms, which we will do in our regression analyses.

We next take advantage of the richness of our data to explore some patterns in the data that will provide the reader with a broader sense of where corruption - as captured by investigated firms and investigated RUPs - is most prevalent.

In Appendix Table A1, we show the frequency of investigated RUPs overseeing auctions and the frequency that investigated firms that win auctions, for the two most common sectors in our database, roads and building construction. For both RUPs and firms, investigations are more common in road-building. It is perhaps telling that Bosio et al. [2022] use road construction as their hypothetical contract to study the oversight of procurement processes. Anticipating our later results, we find the opposite pattern for contracts that we classify as prone to corruption (i.e., Discretion $=1$ ): these are more common in the buildings sector.

We next examine whether contracts are more likely to involve investigations based on whether the official overseeing the contract was born in that locality, in Appendix Table A1, which might serve as a proxy for access to local networks that might facilitate corruption. We include this comparison in the second part of Appendix Table A1, where we show that locally-born RUPs are indeed more likely to be investigated. Paralleling the prior analysis, we also show that discretion is lower in contracts overseen by local RUPs.

Finally, we turn to a geographic comparison of auction procedures and outcomes, where we again explore both the prevalence of investigated firms and RUPs, and also anticipate the limits to discretion that may exist if corruption is more common. In our geographic comparisons, we can more plausibly take as given that different parts of Italy have historically been associated with higher corruption. Specifically, in Table 1 we compare auction characteristics for South, Central, and North Italy over our full sample period, 2000-2016. Given the South's long history with, and reputation for, corruption, it is perhaps unsurprising that the fraction of auctions overseen by procurement officials suspected of corruption is notably higher in the South relative to Central and North Italy (first row). In the second row, we show the mean fraction of auctions won by firms suspected of corruption. Again, there is a North-South gradient: investigated firms are more likely to win in the South relative to the North and Central regions, though the difference is much more modest than for RUPs. We next turn to the selection of auctions that, in the preceding figure, were associated with higher levels of corruption, i.e., Discretion $=1$ auctions (recall these are DiscretCrit $=1$ and DiscretProclown $=1$ auctions). Notably, these are far more common in the (relatively less corrupt) North 
(third row). In the last two rows, we look at the North-South choice of discretion for auctions administered by investigated procurement officials and clean (non-investigated) officials. Interestingly, across all areas investigated administrators select discretion more often. The relative rarity of "corruptible" auction procedures in the high-corruption South suggests another potential explanation for the muted link between the increase in negotiated auctions and investigated winners: problematic auctions are used less often in locales where they are more apt to be corrupted.

Naturally, these patterns are merely presented as motivation - there are many factors that could account for the North-South differences we observe. We will attempt to account for these factors when we focus on within-PA variation in our regressions. But overall, the patterns in Table 1 and Appendix Table A1 offer descriptive evidence that is broadly consistent with the regression analysis reported in the next section, and which will be useful for understanding how Italian authorities may have limited the extent to which discretion can be exploited by officials for private gain.

Before proceeding to our regression results, we conclude this section with a presentation of the summary statistics for our data in Table 2. Panel (A) provides summary statistics at the auction level for the whole sample of just over 200,000 auctions. Of these, $37 \%$ are done using negotiated procedures, and $83 \%$ of auctions use the price-only criterion. Investigated firms are awarded $17 \%$ of the contracts and investigated RUPs administer $10 \%$ of all auctions. The average number of bidders across all auctions is 27 , but for negotiated procedures, the average number of invited bidders is 7 . Relative to an average reserve price of nearly $€ 1$ million, the final price entails, on average, a $7 \%$ cost overrun (relative to the initial reserve price), and the average delay is $63 \%$ relative to the originally specified contractual duration.

Panel (B) reports summary statistics at the level of the public administrations awarding contracts. We observe 14,024 administrations out of which $16 \%$ have at least one RUP suspected of corruption. $52 \%$ of public administrations are in the North, $35 \%$ in the South, and $13 \%$ in the Center. In terms of administration type, local PAs award most contracts, with municipalities representing $57 \%$ of the PAs in the dataset (though they administer only $53 \%$ of auctions). Of the 7,985 municipalities observed, $67 \%$ have fewer than 5,000 inhabitants, while only $1 \%$ of municipalities have more than 60,000 inhabitants. The average administration awards 15 contracts over the sample period, with an average total value of nearly $€ 1.5$ million. 


\section{Empirical Analysis}

We now turn to examine the relationship between the choice of auction mechanism to firms and officials suspected of corruption. We first examine the link from the type of auction to whether it is won by an investigated firm, and then turn to look at the choice of auction types by investigated public officials. We will then use the framework in Section $\mathrm{V}$ to interpret these patterns in terms of the tradeoff invoked by expanding discretion.

\section{IV.A Discretionary auctions and investigated winners}

We employ throughout variants on the following specification:

$$
\text { InvestigatedFirm }_{x a y}=\beta \text { Discretion }_{x a y}+\text { Controls }_{x a y}+\alpha_{a}+\gamma_{y}+\varepsilon_{x a y}
$$

for auction $x$ conducted by contracting authority $a$ in year $y$. We include contracting authority fixed effects to account for local differences in the choice of procurement mechanisms as well as (localized) differences in corruption; the year fixed effects absorb shifts over time in the prevalence of discretionary contracts as well as corruption. Finally, as controls, we include a linear term for the logarithm of the reserve price as well as a set of fixed effects for various size thresholds. ${ }^{26}$ We use robust standard errors clustered at the level of the contracting authority throughout.

Because this expression employs a large number of contracting authority fixed effects, our empirical approach might raise concerns if discretion only varies within a small, selected pool of administrations. However, as shown in Table 3, this is not the case: many administrations experience variation in the various measures of discretion analyzed and, moreover, these administrations do not appear to be selected in any obvious way.

We present these results in Table 4. In columns (1) and (2) we show results using DiscretProclown and DiscretCrit respectively as our measure of discretion, and in column (3) we include both as covariates. The coefficient on each variable is stable across all specifications and significant at least at the $1 \%$ level in all cases. The coefficient

\footnotetext{
${ }^{26}$ In practice, the point estimates we report below are quite insensitive to the inclusion/exclusion of these covariates. For example, if we include only year fixed effects as controls, the estimate is about 0.003 higher than what we report below, a difference of about 30 percent as compared to the fully saturated specifications. Finally, we note that our results are unaffected by the inclusion of a control that captures whether a firm is connected to a politician at the local, regional, or national level. We prefer not to include this variable in our main specifications, as we believe it suffers from a bad control problem (firms intent on engaging in corruption will coopt politicians), but present results that include it in Appendix Table A6.
} 
on DiscretProc lowN $_{\text {of }} 0.02$ implies that auctions employing negotiated procedures with "too few" invited bidders are associated with a $12 \%$ higher probability of being won by an investigated firm. The coefficient on DiscretCrit is approximately half as large. ${ }^{27}$ In column (4) we add the variable, DiscretProc highN $_{\text {, }}$, as a covariate, which denotes auctions that are done via discretionary procedures, but with the requisite number of bidders. The coefficient on DiscretProchighN is very small (0.0013), and we can reject at the $99 \%$ level that it is even half as large as the coefficient on DiscretProc low $_{\text {. }}$ (We can reject at the $0.1 \%$ level that the two coefficients are equal). Finally, in column (5) we use the summary discretion measure, Discretion, pooling together both DiscretProclown and DiscretCrit. The coefficient of 0.012 implies that more discretionary auctions are associated with a $7 \%$ higher probability of being won by a criminal firm. Columns (6) - (10) repeat these analyses, limiting the sample to auctions administered by municipal councils, as this is the sample we will focus on in analyzing whether the patterns we document are robust to controls for municipal attributes. The patterns are broadly similar, though the coefficients on the two distinct discretion variables are much closer in magnitude, and the coefficient on the pooled discretion measure is larger.

The correlation between the choice of discretionary auctions and the selection of an investigated firm as winner is robust to a range of considerations. In addition to procurement administration fixed effects, we may include region $\times$ year or even province $\times$ year fixed effects (a total of 1,770 additional fixed effects), and the point estimates remain quite similar. We may also amend the definition of InvestigatedWinner to make it more - or less - inclusive. In Appendix Table A2, we show the results using a definition that focuses more narrowly on corruption (restricting attention only to firms investigated for (i) corruption, malfeasance, and embezzlement or (ii) abuse of power and undue influence, but excluding those investigated for (iii) violations in public auctions) and in Appendix Table A3, we expand the definition to include firms associated with individuals suspected of waste management crimes. The inclusion of the latter group is at the suggestion of anti-corruption authorities, who indicated to us that it is a common area for organized crime and corruption. In both cases, we observe broadly similar patterns to those reported in Table 4. While we see a measure of corruption based on investigations rather than realized convictions as preferable, since the former includes cases of likely malfeasance that nonetheless cannot be prosecuted, we also consider a specification in which the outcome is an indicator variable denoting that the auction winner was convicted for corruption. Note that conviction is a much rarer event relative to investigations - the mean conviction rate is only 0.017 (standard deviation 0.13 ) as compared to 0.17 (standard deviation 0.38)

\footnotetext{
${ }^{27}$ One possible explanation for this weaker relationship is that first-price auctions with few bidders also afford opportunities for directing a contract to very specific firms via the tailoring of the requirements to make a bid, rather than the criteria used to evaluate the bids.
} 
for investigations. Given the low conviction rate, the point estimates in Table A4 are commensurately smaller relative to those in our main results, but the broad patterns are similar, even if the estimates do not generally reach statistical significance at conventional levels. Finally, in Appendix Table A5 we include procurement-authority-by-year fixed effects. While being more demanding and restrictive, this specification greatly improves identification, as it allows us to take into account any unobserved time-varying shocks at the authority level. Notably, results are remarkably similar to the ones of Table 4.In Appendix Table A7, we explore whether the higher rate of investigated winners for DiscretProc lown and DiscretCrit auctions is the result of selection into the participants' pool or selection of the winner (conditional on the pool of bidders). We run a specification analogous to the one in equation (1), but now using data at the bidder level:

$$
\text { InvestigatedBidder }_{\text {ixay }}=\beta \text { Discretion }_{x a y}+\text { Controls }_{\text {ixay }}+\alpha_{a}+\gamma_{y}+\varepsilon_{x a y}
$$

As noted in our data description, bidder-level data are only available starting in 2011. We observe a positive coefficient on DiscretProc lown across all specifications, with a value of $0.011-0.012$ (significant at the 1 percent level). No other variable is significant. These findings provide some suggestive evidence that (uncompetitive) negotiated procedures may be corrupted by directing invitations to investigated firms, whereas scoring rule auctions may be corrupted by tailoring the selection criteria to favored firms, rather than foreclosing entry into bidding.

\section{IV.B Investigated administrators and the choice of discretion}

In Table 5, we explore the choice of discretion as an auction mechanism. We begin with results that most closely parallel those of the preceding section, with public administration fixed effects. In column 1 the dependent variable is Discretion, while in columns 2 and 3 we distinguish between the effect on DiscretProc lown and DiscretCrit. In all cases, the coefficient on InvestigatedRUP is positive (significant at least at the $5 \%$ level), indicating a higher use of discretionary auctions; comparing columns 2 and 3, the point estimate is more than twice as high for discretionary criterion auctions, though the base rate of discretionary criterion auctions is also much higher. ${ }^{28}$

In the remainder of the table, we introduce InvestigatedPA as a covariate. Since this variable varies only at the PA level, we can include only coarser fixed effects. In Table 5 we employ fixed effects for each of the country's 20 regions, and in Appendix

\footnotetext{
${ }^{28}$ In Table A8, we explore the direct effect of InvestigatedRUP on investigated winner. The effect is positive and significant, albeit small in magnitude. The estimates for the other coefficients remain qualitatively identical to those in the baseline estimates in Table 4.
} 
Table A9 we use a finer partition, with fixed effects for each of 110 provinces. (Recall that, for a subset of procurement authorities (hospitals, highways, and so forth), we do not have a mapping to a specific geographic location; thus auctions conducted by these PAs are dropped from specifications with region or province fixed effects.) In columns 4 and 5 we include InvestigatedRUP and InvestigatedPA respectively as covariates, with Discretion as the outcome variable. Note that, by definition, these variables are positively correlated $(\rho=0.45)$. It is intriguing, therefore, that their coefficients are of opposite sign (significant at the 1\% level). Specifically, PAs that have had at least one administrator suspected of corruption are $7.7 \%$ less likely to use discretionary auctions (a coefficient of 0.017 relative to a base rate for Discretion of 0.22 ) while, for a given municipal council, a corrupt administrator is $8.6 \%$ more likely to use a discretionary auction $(0.019 / 0.22)$. In column 6 , we include both variables - as might be expected given their strong positive correlation, in this specification the magnitude of each coefficient increases, nearly doubling for both InvestigatedRUP and InvestigatedPA. Columns 7 and 8 repeat the specifications from column 6 , which include both InvestigatedPA and InvestigatedRUP, but using our two distinct discretion variables as the outcomes, DiscretProc lown and DiscretCrit. In these specifications, the relationships between both variables and discretion are driven by the selection of DiscretCrit auctions (though we refer back to column 1 to emphasize that, with finer fixed effects, there is a discernable positive relationship between InvestigatedRUP and the choice of discretionary procedures). ${ }^{29}$

\section{IV.C The direct benefits and costs of discretionary auctions}

We now turn to describe the benefits of discretion. The main official motivation for encouraging negotiated procedures is speeding up administrative procedures. The administrative burden is lighter for negotiated procedures than with open auctions: PAs can publish shorter, less detailed calls for tenders, and these calls have shorter minimum mandatory publicity periods (about half of the 52 days typically required for open tenders, but even less if certain conditions are met). The selection of the winning bid is also faster, as typically the RUP selects the winner directly from among a small set of bidders. At the opposite end of the spectrum, scoring rule auctions require the creation of ad hoc commissions to evaluate bids and select winners.

A different margin along which discretion can benefit PAs is by helping to reduce the adverse selection effects of open, competitive bidding. As mentioned earlier, incomplete contracts and non-contractible quality are a near-defining feature of contract procure-

\footnotetext{
${ }^{29}$ Replicating the specifications in Table 5 using as dependent variable DiscretProc, we find no relationship between investigated RUPs or PAs and this outcome; see the Appendix Table A10.
} 
ment. A first-price open auction can be the most problematic allocation mechanism when even just one opportunistic firm participates. Although several institutional features in the system are geared toward limiting the problem of "too good to be true" bids, discretion in selecting participants and bids can be a powerful tool (it is indeed the pillar of private contracting).

We provide some indication of these potential benefits of discretion in Table 6. The table presents the results of specifications that parallel those presented above, using the inverse hyperbolic sine of the contract's delay in implementation $(A \sinh ($ Delay $))$, the discount offered by the winning firm, and the extra cost realized at the end of the contract as outcomes, in place of InvestigatedWinner. ${ }^{30}$ While delay is a highly imperfect indication of performance - for example, it makes little sense to include DiscretCrit as an explanatory variable, since execution time may be part of the scoring rule to evaluate contracts - in the absence of ex-post quality evaluations of contracts, it nonetheless provides one objective indication of the winning firm's performance. ${ }^{31}$

Table 6, column (1) includes Discret as an explanatory variable, along with fixed effects for procurement administration and year, and flexible reserve price controls. As would be expected if discretion speeds the completion of a contract, the coefficient on Discret is negative, though small in magnitude and only borderline significant $(p<$ 0.07). We distinguish between DiscretCrit and DiscretProc low $N_{\text {in }}$ column (2), and find that there is a much stronger negative relationship for negotiated procedures - recall that, as we noted above, it is hard to interpret the relationship between discretionary criterion and delay, as completion time may be a component of the scoring rule used to evaluate bids. In column (3) we add a control for negotiated procedures - recall that this captures auctions in which bidders must be invited to participate in the auction, whereas

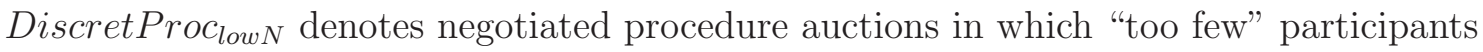
are invited. Interestingly, once one accounts for whether an auction is a negotiated

\footnotetext{
${ }^{30}$ All three outcomes are available only for a subsample of auctions. Therefore, we also test the robustness of our main results in this restricted sample. Specifically, Table A12 replicates the results of Table 4 for the subsample of auctions for which we have either Delay, Discount, or Extra Cost information. As an additional check, in Table A11 we show that neither InvestigatedWinner nor InvestigatedRUP predict the presence of outcome data - indeed if anything such data are more likely to be available in these cases. Finally, since we present our earlier results for the full sample of PAs as well as for municipalities only, in Table A13 we repeat the analysis but limiting the attention to contracts awarded by local authorities. Results are very similar to those reported below.

${ }^{31}$ The absence of quality evaluation imposes a limit on the interpretation of our results, but no such data are typically available. With a few notable exceptions where direct evidence on quality of the procured contracts is observed, time delays and cost overruns are generally used as proxies for quality by government agencies and most of the academic literature when the focus is on complex contracts (as opposed to simpler contracts for the procurement of standardised goods). For instance, delays are the main outcome in Lewis and Bajari [2011], while cost overruns are the proxy for quality in Mohamed et al. [2011], Iimi [2013], Bajari et al. [2014], Schoenherr [2019], Jung et al. [2019].
} 
procedure - which itself is associated with much shorter delays - there is little incremental effect of DiscretProc lown on delay.

The remaining columns of Table 6 repeat the regression analysis for the two other outcomes. We observe a clear negative and economically large impact of discretion on winning discounts: the coefficient on Discret implies a 4 percentage point lower discount, relative to an average winning discount of 18 percent. Column 6 shows that most of the drop is associated with discretionary criteria and, to a lesser extent, discretionary procedures with too few bidders. Negotiated procedures with the appropriate number of bidders more generally are associated with lower discounts, as indicated by the negative coefficient on DiscretProchighN, but the size of the effect is about half of that of the discretionary criterion. Thus, it appears that discretion has a direct impact on increasing the price paid by PAs by a significant amount, which could result from discretion limiting competition, or if discretion is used to select higher quality bids. In the next and final section of the paper, we will relate this increase of public cost to the (potential) benefit for a corrupt RUP.

Finally, notice that the final price, inclusive of cost overruns, is essentially unaffected by the choice of discretion, as the estimated coefficients are either not significant or, in the case of discretionary criterion, significant and negative, but small in magnitude. ${ }^{32}$

\section{Conceptual Framework: Corruption and Oversight}

In this section, we lay out a very simple and intuitive model to interpret our empirical results. Naturally, given the correlational nature of our analysis, we cannot link our findings definitively to a particular interpretation; rather, the goal of this section is to illustrate that our disparate findings can be explained via a very standard principal-agent framework.

The patterns documented above may be organized through the lens of the theory of delegation, originally laid down by Holmstrom et al. [1982] and applied to political economy settings in particular as outlined in Bendor et al. [2001] and Huber and Shipan [2006]. Holmstrom et al. [1982] in particular describes the classical optimal delegation problem with no transfers: a central monitor (the principal) trades off the benefits of an

\footnotetext{
${ }^{32}$ We are implicitly taking the assignment of a contract by an investigated RUP or assignment to an investigated firm as social harmful in itself, and exploring the extent to which other benefits or costs arise as a result of the types of auctions we associate with corruption. We may in addition look at the direct correlation between auction outcomes and whether a RUP or firm is investigated, as some indication of whether corruption imposes a direct social cost. We provide these analyses in Appendix Table A14. As with discretion, both investigated RUPs and investigated firms are associated with smaller discounts. Interestingly, there is no offsetting benefit in terms of delay.
} 
agent's discretion against the costs of self-dealing, without being allowed to link transfers to the realized outcomes. This framework plausibly resembles the situation of the procurement officers in our data, whose wages and careers are only weakly associated with the performance of the contracts they supervise. ${ }^{33}$

Our simplified version of this style of model considers the task of a central monitoring authority (such as a regional government) that aims to limit corruption. Discretion makes it easier for officials to abuse their positions if they choose to do so, but also empowers civic-minded officials to execute contracts more efficiently. The principal has limited information on the infrastructure needs of lower-level governments (e.g. municipalities), and hence receives a noisy signal as to the benefits of running an auction using discretionary methods. As a result, infrastructure provision may be more efficient if local officials - who have a stronger local presence and/or expertise - choose the auction format. The misalignment results from potential self-dealing by corrupt local officials.

More specifically, we assume that a central authority may choose whether to allow procurement officials in administration $a$ to run an auction with greater discretion. Let $d$ be a parameter that captures the potential benefit from discretion in implementing the project so that, for example, the value of the project is $v$ in the absence of discretion and $v+d$ if discretion is allowed. While $v$ is perfectly observed, $d$ is known only to the official overseeing the project; others (including enforcement officials) observe only $\hat{d}=d+\epsilon$. It is possible that $d<0$, so that discretion is socially destructive, whereas monitors may still receive a positive signal. This assumption allows for the case that a civic-minded official will choose not to use a discretionary auction.

A further cost of discretion is that it provides opportunities for self-dealing, which may be obfuscated precisely because of uncertainty in the value of discretion. We do not aim, at this level of abstraction, to model the firm-official interaction. In our simple framework, one can think of corrupt officials extracting kickbacks from firms, or prospective bidders corrupting procurement officials by offering bribes. For a potentially corrupt administrator, we think of their theft decision as dictated by the private returns from stealing $s$, less a punishment cost which is a function of detection probability $e_{a}$, which is a public-administration-specific parameter, so that his payoff function will be: $\pi=s-e_{a} s^{2}$. In the internal solution, this payoff function leads to a theft choice of $s^{*}=1 / 2 e_{a}$.

We assume that the monitoring authority may constrain a public administration from utilizing discretionary auctions by setting a threshold for the signal of discretion's benefit, accounting for both stealing (which is a function of the public administration's

\footnotetext{
${ }^{33}$ Our model is also very much in the spirit of the framework of Bosio et al. [2022], which documenting how limits to discretion are effective in low-public sector capacity countries, but not in high-capacity ones. Our results fit in this framework, to the extent that the risk of public corruption is negatively correlated with public sector capacity.
} 
enforcement efforts, $e_{a}$ ) and the probability that a contract is corrupted (which depends on the share of corrupt public officials in administration the administration, $\left.p_{a}\right)$. A risk-neutral monitor seeking to maximize the project value will then set a threshold $\hat{d}^{*}=p_{a} / 2 e_{a}$.

This model captures the simple intuition that, in locations with weaker enforcement or a higher prevalence of corrupt agents (which plausibly are correlated), there will be a higher threshold set for the use of discretionary auctions. Hence, differences among administrations in $\left(p_{a}, e_{a}\right)$ might lead to instances in which the monitor restrains discretion in situations in which it would be socially optimal to allow for it. But it also follows that corrupt officials will use discretionary auctions more often since, by definition, noncorrupt officials use discretion only when $d>0$ whereas corrupt ones will do so whenever the monitor allows it (i.e., the threshold is high enough).

\section{V.A Re-evaluating the overall effect of increased discretion}

In Section IV.A, we found that negotiated contracts with many bidders - which constitute the vast majority of auctions with discretion - were won by investigated firms at the same rate as open price-only auctions. While negotiated contracts with "too few" bids and scoring rule auctions were won more often by investigated firms, we also observed in Section IV.B that regional governments may take steps to limit the use of these mechanisms in locales that are vulnerable to corruption.

These findings naturally return us to the question of whether the limits to discretion imposed by procurement regulations were too strict. Procurement regulations are the result of a complex web of rules determined by the European Procurement Directives, Italy's national procurement law and, in most cases, local rules (at the regional, provincial, and even municipality levels; see Figure A1). At the local level, there are many examples of rules either limiting or expanding RUP's discretion: for instance, Calabria, Campania, and Sicily, the three regions with endemic criminal organizations, passed various regional guidelines and regulations limiting the use of discretionary procedures or criteria.

The most straightforward setting to explore the aggregate consequences of changing the limits to discretion is to focus on the nationwide reforms that loosened the rules on the use of negotiated procedures during the late 2000s. While our earlier discussion emphasized the role of a local (regional) monitor that could set the minimum required expected benefit from discretion to activate it ( $\hat{d}^{*}$, in the model above), we also discussed the existence of national rules which set strict monetary thresholds on contract values to determine which ones may be awarded via discretionary methods. This type of rule is typical in procurement regulations, and indeed a similar setup is present in the US for 
accessing the Simplified Acquisition Procedure. ${ }^{34}$

The motive behind this form of regulation can be easily understood if one presumes that the national regulator does not even observe the signal of the value of discretion for a specific project, and we further augment our basic model to assume that the benefits to the agent from stealing increase with project size. ${ }^{35}$ In this augmented framework, setting a maximum project value beyond which discretion is forbidden can serve to limit the risks of stealing.

Note, however, that this additional rigidity imposed at the national level comes at the cost of limiting discretion for local administrations and RUPs that would use it for public benefit. This rigidity may further be excessive (relative to the social welfare optimum) if political economy considerations lead to a large weight on theft by national bureaucrats and politicians. ${ }^{36}$ A similar argument may be applied to a bureaucrat with career concerns and reduced performance incentives: discretion will be under-utilized if it increases the probability that an official will face a corruption investigation which, in the Italian context, would defer any promotion until acquittal, without sufficient offsetting rewards. ${ }^{37}$

These changes led to only a modest increase in either of the auction types that we have flagged as associated with corruption. For example, comparing auctions held prior to 2008 versus those held in 2011 and later, the fraction of auctions for which DiscretProc $=1$ or DiscretCrit $=1$ increases from $20.5 \%$ to $23.6 \%$ : while discretionary

\footnotetext{
${ }^{34}$ In the US, since the Federal Acquisition Streamlining Act of 1994, Simplified Acquisition Procedures (SAP) were introduced to promote efficiency and economy in contracting by reducing administrative costs and unnecessary burdens for agencies and contractors. Under the SAP, contracting officers can select private contractors in more informal ways, for instance by getting oral (rather than written) quotes and selecting the winner without the need for a formal comparative assessment among quotes. The SAP applies to purchases of supplies or services whose anticipated dollar value does not exceed the Simplified Acquisition Threshold, which has increased over time, reaching $\$ 150,000$ as of 2014, and making purchases under the SAP an even larger portion of federal procurement.

${ }^{35}$ Under this modification, the optimal stealing would become $s^{*}=\frac{v}{2 e_{a}}$, where $v$ is the baseline project size, as in Section V.

${ }^{36}$ For example, reelection concerns may lead a politician to limit stealing per se - beyond its impact on project outcomes - because of the negative publicity from revelations of corruption in public works. The responsiveness of politicians to corruption scandals has been documented, in particular, through a series of papers exploiting the richness of Brazilian data on corruption audits, including Avis et al. [2018] and Ferraz and Finan [2011]. The former study documents a significantly lower rate of corruption in municipalities in which mayors can run for reelection, while the latter estimates a structural model of agency which illustrates that the reduction in corruption after an audit comes primarily from the perceived non-electoral costs of engaging in corruption.

${ }^{37}$ This is the well-known problem of low-powered incentives for public employees, which has been documented across many countries and institutions (see, for instance, the analysis of Indian bank nationalizations by Banerjee et al. [2004]). The problem may be exacerbated by the initial selection of individuals choosing to become bureaucrats (as analyzed, for instance, through a randomized study of initial public sector wage offers in Mexico by Dal Bo et al. [2013]) as well politicians (see the recent review by Dal Bo and Finan [2018]).
} 
procedure auctions increased substantially (from $0 \%$ to $12.7 \%$ ) this increase was largely offset by a substitution away from discretionary criterion (scoring rule) auctions. Taken at face value, our regression coefficients imply a 1.5 percentage point increase in auctions won by investigated firms for the incremental 3.1\% of auctions conducted via discretionary procedure or criterion. This calculation leads to a $0.05 \%$ increase in investigated winners overall $(0.031 \times 0.015)$. Given our proposed framework, these results are unsurprising. Indeed, recall that the increase in negotiated procedure auctions with the legally mandated number of bidders is about 50\% between 2008 and 2011. Thus, if these led to even small efficiency gains relative to open first-price auctions, it would more than offset the loss from the very small increment in corrupted auctions. We find this to be quite plausible given our findings on the improvements in contracting quality from discretion, such as a 14 percent reduction in delays.

\section{Conclusions}

We present evidence suggesting that discretion, to the extent that it limits competition, is associated with higher suspected corruption in procurement. We show that these auctions are chosen more often by officials suspected of corruption, and less often in public administrations in which at least one procurement official has been investigated for corruption.

We see several main takeaways from our findings. First, given the central role played by competition in the patterns we document, our results argue against certain classes of models which emphasize bribery as a means of competing with other bidders, and those that model corruption as the outcome of a competitive (and efficient) bidding process in which the best firm is willing to bribe the most to secure a contract. Second, presuming there is enough competition (i.e., sufficient bidders), rigid constraints on auction officials' discretion (e.g., via minimum contract size thresholds) may be costly tools that, at least based on our measure, have a modest impact on corruption. Indeed, our rough assessment based on the costs and benefits of discretion suggest that it is likely under-utilized in our setting. In our view, this result is unexpected, particularly for a country like Italy, which has been traditionally characterized by high levels of corruption, given its level of development.

We also see a number of avenues for future research. For example, we wish to better

understand the costs invoked by rules to limit corruption as a step to further clarifying the trade-offs that result from anti-corruption policies. Furthermore, in this first assessment of the link between discretion and corruption, we have taken a broad view of the data, and done so in a correlational framework. We hope that the patterns we document may offer 
inspiration for future work with a clearer causal design or equilibrium analysis, to further probe our basic findings and proposed framework. In a similar spirit, future research may also provide deeper insights into the specific mechanisms that underlie the correlations we document.

Finally, our findings have a number of policy implications. In particular, the difference in outcomes of negotiated auctions with "many" versus "few" bidders is potentially important for assessing the overall costs and benefits of discretion. Indeed, our findings suggest that discretion itself is not necessarily problematic, but rather discretion combined with foreclosure of competition: scoring rule auctions limit competition by tailoring contract terms to a specific firm's capabilities, while negotiated contracts with few invited bidders by construction limit the competitive bidding process. Hence, the use of more discretionary auctions should go hand in hand with more stringent requirements for fostering firm participation.

More generally, in both developed and developing countries, the legal and regulatory frameworks governing public procurement have a profound impact on the interactions between governments and private sector firms, and ultimately on the effectiveness of government service delivery. In 2013, the World Bank began publishing an annual study - Benchmarking Public Procurement - which analyzes the public procurement regulations of about 180 economies; these reports real considerable heterogeneity across countries. Our results help to explain why such a variety of systems exist, as we argue that trade-offs in the choice of procurement rules (in particular the extent to which discretion is allowed) depend critically on the local conditions (in particular the extent of corruption and also the monitoring effectiveness).

By the same reasoning, the same rules may have highly heterogeneous effects, depending on the context where they are used. In this respect, one noteworthy element of our analysis for policy design is the finding of higher corruption risks associated with scoring rule auctions. In the European Union, after 10 years of negotiations between member states, a new Procurement Directive was published in 2014. At its core, it features a switch from the previous highly rigid system of price-only open auctions to a more discretionary system, in which scoring rule auctions are effectively the default. The effects of this change have still to be studied, as its full implementation is quite recent. Member states are permitted an adjustment period to adopt the Directive in their legislation and Italy, for instance, implemented the new rules only in April 2016. However, our results indicate that the goal of creating a common legislative framework in the EU to foster economic integration and cross-border procurement may come at a cost of requiring regulations that are not necessarily well-suited to all institutional environments - the new rules may result in regulations that for some areas lead to substantially higher 
corruption risk, while for other areas, the one-size-fits-all regulations may not allow for sufficient discretion. Our estimates are a first step in quantifying the elements of this important trade-off. 


\section{References}

Emmanuelle Auriol, Stéphane Straub, and Thomas Flochel. Public procurement and rent-seeking: the case of paraguay. World Development, 77:395-407, 2016.

Eric Avis, Claudio Ferraz, and Frederico Finan. Do government audits reduce corruption? estimating the impacts of exposing corrupt politicians. Journal of Political Economy, forthcoming, 2018.

Patrick Bajari, Stephanie Houghton, and Steven Tadelis. Bidding for incomplete contracts: An empirical analysis of adaptation costs. American economic review, 104(4): 1288-1319, 2014.

Audinga Baltrunaite, Cristina Giorgiantonio, Sauro Mocetti, Tommaso Orlando, et al. Discretion and supplier selection in public procurement. Technical report, Bank of Italy, Economic Research and International Relations Area, 2018.

Oriana Bandiera, Andrea Prat, and Tommaso Valletti. Active and Passive Waste in Government Spending: Evidence from a Policy Experiment. The American Economic Review, 99:1278-1308, 2009.

Oriana Bandiera, Michael Best, Adnan Khan, and Andrea Prat. The allocation of authority in organizations: A field experiment with bureaucrats. mimeo, 2020.

Abhijit Banerjee, Esther Duflo, and Shawn Cole. Banking reform in india. mimeo, 2004.

Edward C. Banfield. Corruption as a feature of governmental organization. Journal of Law and Economics, 18(3):3, 1975.

Pranab Bardhan and Dilip Mookherjee. Decentralization, corruption and government accountability. International handbook on the economics of corruption, 6:161-188, 2006.

Jonathan Bendor, Amihai Glazer, and Thomas Hammond. Theories of delegation. Annual review of political science, 4(1):235-269, 2001.

Alon Bergman, Matthew Grennan, and Ashley Swanson. Lobbying physicians: Payments from industry and hospital procurement of medical devices. Working Paper 29583, National Bureau of Economic Research, December 2021. URL http://www.nber. org/papers/w29583.

Michael Carlos Best, Jonas Hjort, and David Szakonyi. Individuals and organizations as sources of state effectiveness. NBER Working Paper 23350, National Bureau of Economic Research, Cambridge, MA, 2019. URL http://bit.1y/2dlCTyo. 
Erica Bosio, Simeon Djankov, Edward Glaeser, and Andrei Shleifer. Public procurement in law and practice. American Economic Review, 112(4):1091-1117, April 2022. doi: 10.1257/aer.20200738. URL https://www. aeaweb.org/articles?id=10.1257/aer. 20200738.

Sarah Brierley. Unprincipled principals: Co-opted bureaucrats and corruption in ghana. American Journal of Political Science, 64(2):209-222, 2020.

Jonathan Brogaard, Matthew Denes, and Ran Duchin. Political influence and government investment: Evidence from contract-level data. mimeo, 2016.

Alessandro Bucciol, Riccardo Camboni, and Paola Valbonesi. Purchasing medical devices: the role of buyers' competence and discretion. Journal of Health Economics, forthcoming, 2020.

Roberto Burguet, Juan-Jose Ganuza, and Jose G. Montalvo. The microeconomics of corruption. A review of thirty years of research . Barcelona GSE Working Paper Series, 908(May), 2016.

Nicolás Campos, Eduardo Engel, Ronald D Fischer, and Alexander Galetovic. The ways of corruption in infrastructure: Lessons from the odebrecht case. Journal of Economic Perspectives, 35(2):171-90, 2021.

Rodrigo Carril. Rules Versus Discretion in Public Procurement. Working Paper, 2019.

Matias D. Cattaneo, Michael Jansson, and Xinwei Ma. Simple local polynomial density estimators. Journal of the American Statistical Association, 0(0):1-7, 2019. doi: 10.1080/01621459.2019.1635480. URL https://doi.org/10.1080/01621459.2019. 1635480.

Emanuele Colonnelli and Mounu Prem. Corruption and firms: Evidence from randomized audits in brazil. Technical report, 2017.

Timothy G. Conley and Francesco Decarolis. Detecting bidders groups in collusive auctions. American Economic Journal: Microeconomics, 8(2):1-38, May 2016.

Raffaella Coppier, Mauro Costantini, and Gustavo Piga. The role of monitoring of corruption in a simple endogenous growth model. Journal of Labor Economics, 51(4): 1972-1985, 2013.

Decio Coviello, Andrea Guglielmo, and Giancarlo Spagnolo. The effect of discretion on procurement performance. Management Science, 64(2):715-738, 2017. 
Lydia Cox, Gernot J. Mller, Ernesto Pasten, Raphael Schoenle, and Michael Weber. Big g. Chicago Booth Research Paper No. 20-04, Fama-Miller Working Paper, University of Chicago, Becker Friedman Institute for Economics Working Paper No. 2020-36, 2020 .

Ernesto Dal Bo and Frederico Finan. Progress and perspectives in the study of political selection. Annual Review of Economics, forthcoming, 2018.

Ernesto Dal Bo, Frederico Finan, and Martin A. Rossi. Strengthening State Capabilities: The Role of Financial Incentives in the Call to Public Service. The Quarterly Journal of Economics, 128(3):1169-1218, 2013.

Gianmarco Daniele and Gemma Dipoppa. Business below the line: Screening, mafias and public funds. Technical Report No. 2018-98, BAFFI CAREFIN Centre Research Paper, June 2019.

P. Davigo and G. Mannozzi. La corruzione in Italia: percezione sociale e controllo penale. Libri del tempo Laterza. Laterza, 2007. ISBN 9788842083863. URL https://books . google.it/books?id=sIEEAQAAIAAJ.

Francesco Decarolis. Comparing procurement auctions. International Economic Review, 59(2):391-419, 2018.

Francesco Decarolis and Cristina Giorgiantonio. Local public procurement regulations: The case of italy. International Review of Law and Economics, 43:209-226, 2015.

Francesco Decarolis and Cristina Giorgiantonio. Corruption red flags in public procurement: Evidence from italian calls for tenders. 2019.

Francesco Decarolis and Giuliana Palumbo. Renegotiation of public contracts: An empirical analysis. Economics Letters, 132:77 - 81, 2015. ISSN 0165-1765. doi: https://doi. org/10.1016/j.econlet.2015.04.025. URL http://www.sciencedirect.com/science/ article/pii/S0165176515001767.

Francesco Decarolis, Leonardo M Giuffrida, Elisabetta Iossa, Vincenzo Mollisi, and Giancarlo Spagnolo. Bureaucratic Competence and Procurement Outcomes. The Journal of Law, Economics, and Organization, 05 2020. ISSN 8756-6222. doi: 10.1093/jleo/ewaa004. URL https://doi.org/10.1093/jleo/ewaa004. ewaa004.

Rafael Di Tella and Ernesto Schargrodsky. The role of wages and auditing during a crackdown on corruption in the city of buenos aires. The Journal of Law and Economics, 46(1):269-292, 2003. 
Simeon Djankov, Tania M. Ghossein, Asif Mohammed Islam, and Federica Saliola. Public procurement regulation and road quality. Technical report, National Bureau of Economic Research, 2017.

David Epstein and Sharyn O'halloran. Administrative procedures, information, and agency discretion. American Journal of Political Science, pages 697-722, 1994.

Claudio Ferraz and Frederico Finan. Electoral accountability and corruption: Evidence from the audits of local governments. American Economic Review, 101(4):1274-1311, June 2011.

Joras Ferwerda and Ioana Deleanu. Identifying and reducing corruption in public procurement in the eu, 2013.

Bengt Holmstrom et al. On the theory of delegation. Northwestern University, 1982.

John D Huber and Charles R Shipan. Politics, delegation, and bureaucracy. In The Oxford handbook of political science. 2006.

Atsushi Iimi. Testing low-balling strategy in rural road procurement. Review of Industrial Organization, 43:243-261, 2013.

Hojin Jung, Georgia Kosmopoulou, Carlos Lamarche, and Richard Sicotte. Strategic bidding and contract renegotiation. International Economic Review, 60(2):801-820, 2019 .

Gregory Lewis and Patrick Bajari. Procurement contracting with time incentives: Theory and evidence. The Quarterly Journal of Economics, 126(3):1173-1211, 2011.

Sean Lewis-Faupel, Yusuf Neggers, Benjamin A. Olken, and Rohini Pande. Can electronic procurement improve infrastructure provision? evidence from public works in india and indonesia. American Economic Journal: Economic Policy, 8(3):258-83, August 2016. doi: $10.1257 /$ pol.20140258.

Maxim Mironov and Ekaterina Zhuravskaya. Corruption in procurement and the political cycle in tunneling: Evidence from financial transactions data. American Economic Journal: Economic Policy, 8(2):287-321, May 2016.

Khaled A Mohamed, Shafik S Khoury, and Sherif M Hafez. Contractors decision for bid profit reduction within opportunistic bidding behavior of claims recovery. International journal of project management, 29(1):93-107, 2011.

OECD. Government at a glance 2017. 2017. 
Benjamin A. Olken. Monitoring Corruption: Evidence from a Field Experiment in Indonesia. Journal of Political Economy, 115:200-249, 2007.

Benjamin A. Olken and Rohini Pande. Corruption in developing countries. Annual Review of Economics, 4(1):479-509, 2012.

Juan Ortner and Sylvain Chassang. Making corruption harder: Asymmetric information, collusion, and crime. Journal of Political Economy, 126(5):2108-2133, 2018.

Paolo Pinotti. Clicking on heaven's door: The effect of immigrant legalization on crime. American Economic Review, 107(1):138-68, 2017.

David Schoenherr. Political connections and allocative distortions. The Journal of Finance, 74(2):543-586, 2019.

Robert Wade. The system of administrative and political corruption: Canal irrigation in south india. The Journal of Development Studies, 18(3):287-328, 1982.

World Bank. Benchmarking Public Procurement. 2017. 
Figure 1: Procedures and criteria over time

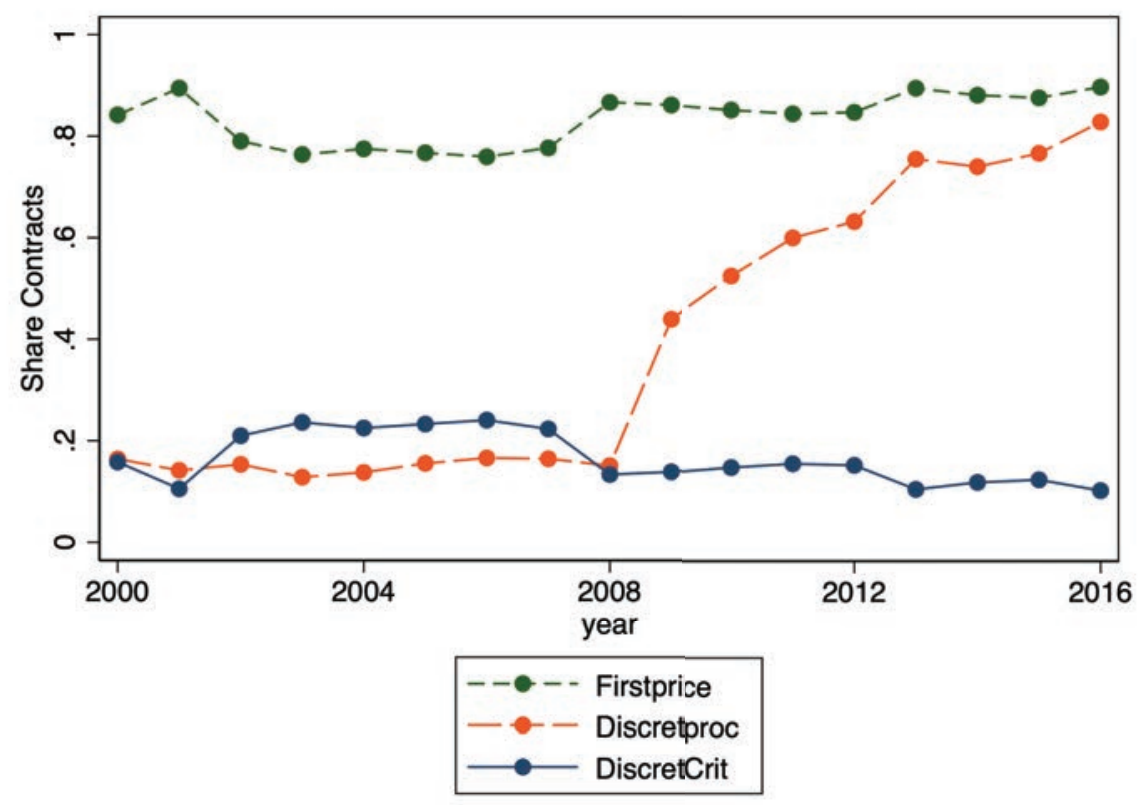

Note: The graph shows, by year, the share of contracts awarded through, respectively, first-price auctions as well as the subset of first-price auctions via negotiated procedure, and scoring rule auctions.

Figure 2: Share of contracts won by investigated firms, by reserve price

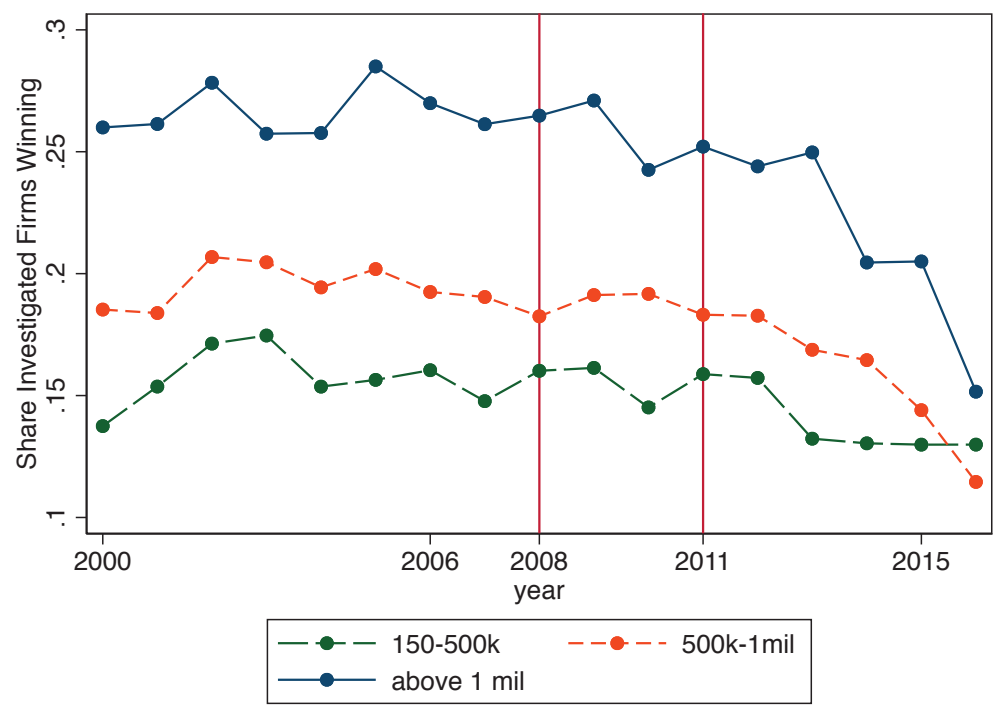

Note: The graph depicts the share of contracts awarded to investigated firms, separately by the reserve price: $€ 150,000$ 500,000; €500,000-1,000,000; and over €1,000,000. 
Figure 3: Share of contracts won by investigated firms, by type of procedure

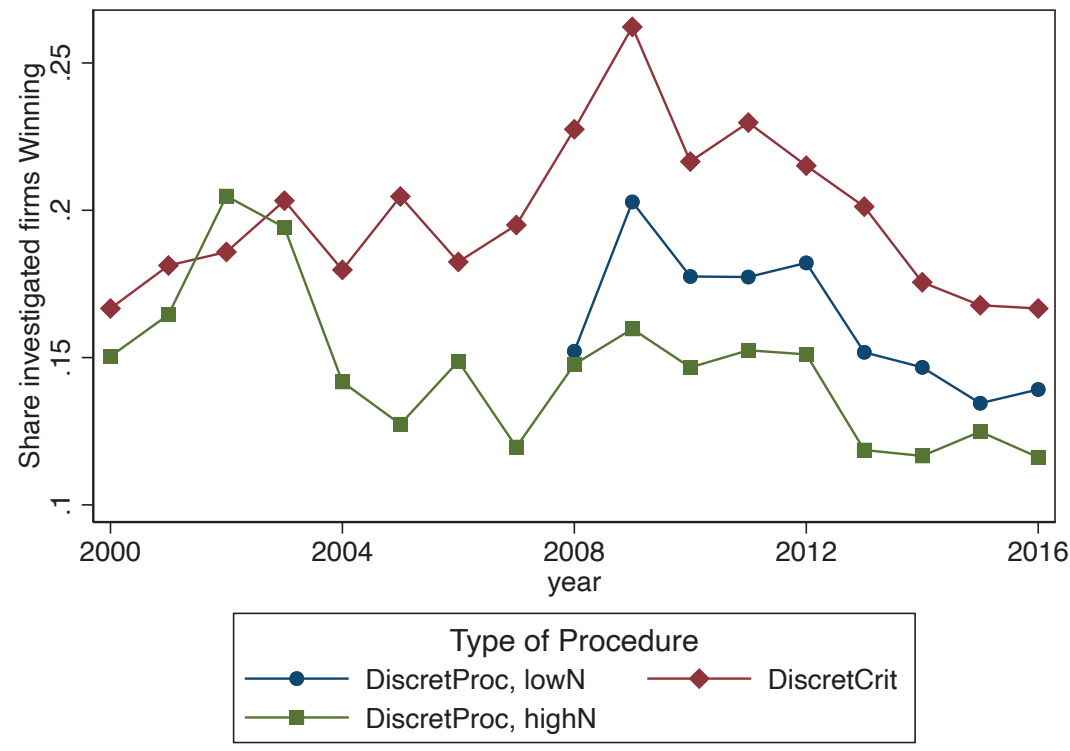

Note: The graph shows the share of contracts awarded to investigated firms, by type of procedure. In particular, the red (diamond) line indicate the share of contracts awarded using DiscretCrit as an awarding criterion won by investigated firms, the blue line (circles) indicates the share of contracts awarded using Discretproclow $N$ as procedure won by investigates firms, and finally the green (square) line indicates the share of contracts awarded using DiscretprochighN as procedure won by investigates firms.

Figure 4: Discretionary procedures over time

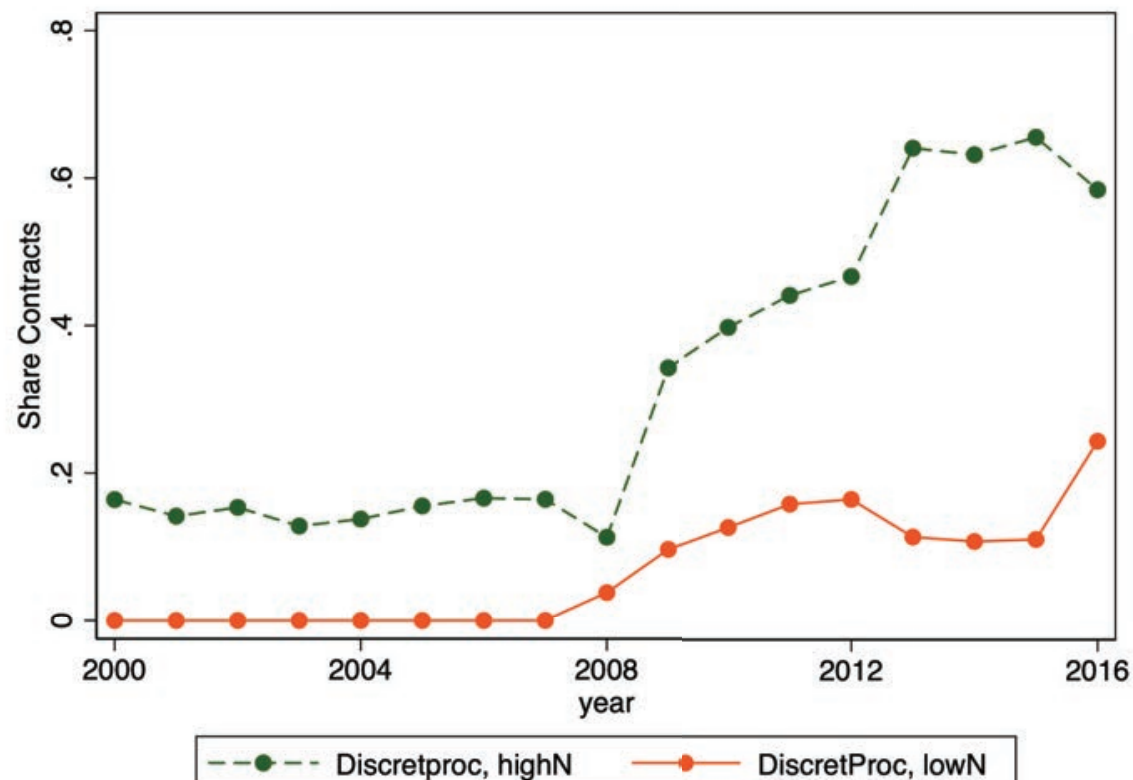

Note: The graph shows the share of contracts awarded through, respectively, Discretionary Criterion, overall Discretionary Procedures and Discretionary Procedures with few bidders, over time. 
Table 1: Summary statistics by geographical area

\begin{tabular}{lccc}
\hline & $(1)$ & $(2)$ & $(3)$ \\
& South & Center & North \\
\hline Investigated RUP & 0.164 & 0.122 & 0.0697 \\
& $(0.370)$ & $(0.328)$ & $(0.255)$ \\
Investigated Winner & 0.175 & 0.161 & 0.168 \\
& $(0.380)$ & $(0.367)$ & $(0.374)$ \\
Discr. Auction & 0.149 & 0.125 & 0.298 \\
& $(0.356)$ & $(0.331)$ & $(0.457)$ \\
Discr. Auction, Investigated RUP & 0.178 & 0.138 & 0.323 \\
& $(0.382)$ & $(0.345)$ & $(0.468)$ \\
Discr. Auction, Clean RUP & 0.143 & 0.124 & 0.303 \\
& $(0.350)$ & $(0.329)$ & $(0.460)$ \\
\hline
\end{tabular}

Note: The sample refers to the universe of contracts awarded by municipalities or other local authorities: $27 \%$ of contracts awarded in the South, $23 \%$ in the Center and 50\% in the North. InvestigatedRUP is an indicator equal to 1 if the public official in charge of the auction has been investigated. InvestigatedWinner is an indicator equal to 1 if the firm winning the auction has been investigated. Discr.Auction denotes auctions for which either a discretionary procedure with fewer than the legally mandated number of bidders (DiscretProclow $)$ or a discretionary criterion (DiscretCrit) has been used to award the auction. 
Table 2: Summary statistics for the full data

\begin{tabular}{|c|c|c|c|c|}
\hline & \multicolumn{4}{|c|}{ A. Auction Level } \\
\hline & \multicolumn{4}{|l|}{$(1)$} \\
\hline & Mean & Median & S.D. & $\mathrm{N}$ \\
\hline Discretion & 0.22 & 0.00 & 0.42 & 211,507 \\
\hline DiscretCrit & 0.17 & 0.00 & 0.38 & 211,507 \\
\hline DiscretProc lowN & 0.06 & 0.00 & 0.24 & 211,507 \\
\hline DiscretProc highN & 0.31 & 0.00 & 0.46 & 211,507 \\
\hline DiscretProc & 0.37 & 0.00 & 0.48 & 211,507 \\
\hline Price Only Auction & 0.83 & 1.00 & 0.38 & 211,507 \\
\hline investigated Firm & 0.17 & 0.00 & 0.38 & 200,092 \\
\hline Investigated RUP & 0.10 & 0.00 & 0.30 & 211,507 \\
\hline No. Bidders & 26.93 & 10.00 & 41.64 & 210,405 \\
\hline No. Invited Bidders & 7.48 & 4.00 & 16.78 & 103,205 \\
\hline Reserve Price (mil) & 0.92 & 0.30 & 14.14 & 195,718 \\
\hline Winning Discount & 18.22 & 16.88 & 11.58 & 192,362 \\
\hline Extra Cost (wrt Base) & 7.01 & 3.37 & 13.85 & 83,088 \\
\hline Contractual Duration & 239.91 & 180.00 & 224.98 & 144,942 \\
\hline \multirow[t]{4}{*}{ Delay (days) } & 135.08 & 73.00 & 220.48 & 108,663 \\
\hline & \multicolumn{4}{|c|}{ B. Administration Level } \\
\hline & $(1)$ & & & \\
\hline & Mean & Median & S.D. & $\mathrm{N}$ \\
\hline Investigated PA & 0.16 & 0.00 & 0.37 & 14,024 \\
\hline Area $==$ North & 0.51 & 1.00 & 0.50 & 9,328 \\
\hline Area $==$ Center & 0.13 & 0.00 & 0.34 & 9,328 \\
\hline Area $==$ South & 0.35 & 0.00 & 0.48 & 9,328 \\
\hline Total N. Auctions, by PA & 15.06 & 4.00 & 68.25 & 14,024 \\
\hline Total Value (in bil), by PA & 148.00 & 17.89 & $2,061.68$ & 14,024 \\
\hline PA_type $==$ Central Admin & 0.02 & 0.00 & 0.14 & 14,024 \\
\hline PA_type $==$ Other Local PA & 0.05 & 0.00 & 0.22 & 14,024 \\
\hline PA_type $==$ Cities & 0.57 & 1.00 & 0.50 & 14,024 \\
\hline PA_type $==$ Transportations & 0.03 & 0.00 & 0.16 & 14,024 \\
\hline PA_type $==$ Hospitals \& University & 0.17 & 0.00 & 0.38 & 14,024 \\
\hline PA_type $==$ Other & 0.17 & 0.00 & 0.37 & 14,024 \\
\hline Population $==$ Pop. up to $5 \mathrm{k}$ & 0.67 & 1.00 & 0.47 & 7,004 \\
\hline Population $==5-10 \mathrm{k}$ & 0.16 & 0.00 & 0.37 & 7,004 \\
\hline Population $==10-20 \mathrm{k}$ & 0.09 & 0.00 & 0.29 & 7,004 \\
\hline Population $==20-60 \mathrm{k}$ & 0.06 & 0.00 & 0.23 & 7,004 \\
\hline Population $==60-250 \mathrm{k}$ & 0.01 & 0.00 & 0.11 & 7,004 \\
\hline Population $==$ above $250 \mathrm{k}$ & 0.00 & 0.00 & 0.04 & 7,004 \\
\hline
\end{tabular}

Note: DiscretProc denotes all negotiated procedures. DiscretProchighN denotes negotiated procedures with at least

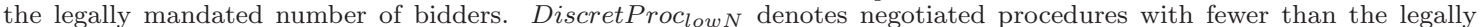
mandated number of bidders. DiscretCrit denotes scoring rule auctions. Discretion denotes auctions for which either DiscretProc low $_{\text {low }}=1$ or DiscretCrit=1. Winning Discount is measured as a percentage of discount relative to the initial reserve price. ExtraCost is measured as a percentage of the initial reserve price. ContractualDuration and Delay are both measured in days. 
Table 3: Summary statistics for identification

\begin{tabular}{lccccc}
\hline & All PAs & & \multicolumn{3}{c}{ Cities } \\
\cline { 5 - 6 } \cline { 5 - 6 } & $(1)$ & & $(2)$ & $(3)$ & $(4)$ \\
& & & South & Center & North \\
\hline Total PAs & 14,384 & & 2,374 & 937 & 4,098 \\
Total PA, > 1 Auction & 10,439 & & 2,140 & 863 & 3,573 \\
At least 1 Discret & 6,845 & & 1,372 & 530 & 2,653 \\
At least 1 DiscretCrit & 5,993 & & 1,290 & 473 & 2,226 \\
At least 1 DiscretProc lown & 3,214 & & 341 & 224 & 1,593 \\
PA w. Variance in Discret & 6,387 & & 1,323 & 526 & 2,495 \\
PA w. Variance DiscretCrit & 5,667 & & 1,243 & 470 & 2,125 \\
PA w. Variance in DiscretProc low N & 3,156 & & 341 & 223 & 1,581 \\
\hline
\end{tabular}

Note: DiscretProc denotes negotiated procedures. DiscretProc lown denotes negotiated procedures with fewer than the legally mandated number of bidders. DiscretCrit denotes scoring rule auctions. Discretion denotes auctions for which either DiscretProc ${ }_{\text {low } N}=1$ or DiscretCrit $=1$.

Table 4: Auction-level regressions, investigated winner

\begin{tabular}{|c|c|c|c|c|c|c|c|c|c|c|}
\hline & \multicolumn{5}{|c|}{ all procurement authorities } & \multicolumn{5}{|c|}{ all city councils } \\
\hline & $(1)$ & $(2)$ & $(3)$ & (4) & $(5)$ & (6) & $(7)$ & $(8)$ & (9) & $(10)$ \\
\hline DiscretCrit & $\begin{array}{l}0.0122^{* * *} \\
{[0.00325]}\end{array}$ & & $\begin{array}{l}0.0132^{* * *} \\
{[0.00328]}\end{array}$ & $\begin{array}{l}0.0133^{* * *} \\
{[0.00328]}\end{array}$ & & $\begin{array}{l}0.0191^{* * *} \\
{[0.00400]}\end{array}$ & & $\begin{array}{l}0.0199^{* * *} \\
{[0.00401]}\end{array}$ & $\begin{array}{l}0.0197^{* * *} \\
{[0.00403]}\end{array}$ & \\
\hline $\operatorname{DiscretProc}_{\text {low } N}$ & & $\begin{array}{l}0.0215^{* * *} \\
{[0.00495]}\end{array}$ & $\begin{array}{l}0.0229^{* * *} \\
{[0.00500]}\end{array}$ & $\begin{array}{l}0.0222^{* * *} \\
{[0.00512]}\end{array}$ & & & $\begin{array}{c}0.0127^{* *} \\
{[0.00592]}\end{array}$ & $\begin{array}{l}0.0152^{* * *} \\
{[0.00589]}\end{array}$ & $\begin{array}{l}0.0163^{* * *} \\
{[0.00583]}\end{array}$ & \\
\hline DiscretProc $_{h i g h N}$ & & & & $\begin{array}{c}0.00183 \\
{[0.00316]}\end{array}$ & $\begin{array}{c}0.00326 \\
{[0.00312]}\end{array}$ & & & & $\begin{array}{l}-0.00321 \\
{[0.00425]}\end{array}$ & $\begin{array}{l}-0.00336 \\
{[0.00423]}\end{array}$ \\
\hline Discretion & & & & & $\begin{array}{c}0.0147^{* * *} \\
{[0.00304]}\end{array}$ & & & & & $\begin{array}{l}0.0199^{* * *} \\
{[0.00367]}\end{array}$ \\
\hline Dep. Var. Mean & 0.170 & 0.170 & 0.170 & 0.170 & 0.170 & 0.170 & 0.170 & 0.170 & 0.170 & 0.170 \\
\hline Observations & 199089 & 199089 & 199089 & 199089 & 199089 & 107994 & 107994 & 107994 & 107994 & 107994 \\
\hline R-sq & 0.118 & 0.118 & 0.118 & 0.118 & 0.118 & 0.130 & 0.129 & 0.130 & 0.130 & 0.130 \\
\hline
\end{tabular}

Note: In all specifications, the dependent variable is an indicator equal to 1 if an investigated firm is awarded the contract. DiscretProc highN denotes negotiated procedures with at least the legally mandated number of bidders. DiscretProclowN denotes negotiated procedures with fewer than the legally mandated number of bidders. DiscretCrit denotes scoring rule auctions. Discretion denotes auctions for which either DiscretProc ${ }_{\text {low } N}=1$ or DiscretCrit $=1$. All regressions include PA and Year fixed effects, a linear control for reserve price (in log) price and 5 dummies for different contract size thresholds (up to $100 \mathrm{k}, 100-150 \mathrm{k}, 150-300 \mathrm{k}, 300-500 \mathrm{k}, 500 \mathrm{k}-1 \mathrm{mil}, 1-1.5 \mathrm{mil}$, over $1.5 \mathrm{mil}$ ) as well as controls for contract characteristics: 4 dummies for category type (Civil Building, Roadworks, Specialized Works or Others), 1 dummy for whether the contract was awarded under urgency and 1 dummy for whether the object of the contract entailed maintenance. Robust standard errors clustered at the PA level are in parentheses. ${ }^{*} p<0.1,{ }^{* *} p<0.05,{ }^{* * *} p<0.01$. 
Table 5: Auction-level regressions, choice of procedure

\begin{tabular}{|c|c|c|c|c|c|c|c|c|}
\hline & (1) & $(2)$ & $(3)$ & (4) & $(5)$ & (6) & $(7)$ & (8) \\
\hline & Discretion & DiscretProc $_{\text {lowN }}$ & DiscretCrit & Discretion & Discretion & Discretion & DiscretProc $_{\text {lowN }}$ & DiscretCrit \\
\hline Investigated RUP & $\begin{array}{l}0.0298^{* * *} \\
{[0.00805]}\end{array}$ & $\begin{array}{l}0.00996^{* *} \\
{[0.00402]}\end{array}$ & $\begin{array}{l}0.0210^{* * *} \\
{[0.00766]}\end{array}$ & $\begin{array}{l}0.0189^{* * *} \\
{[0.00650]}\end{array}$ & & $\begin{array}{l}0.0339^{* * *} \\
{[0.00854]}\end{array}$ & $\begin{array}{l}0.000439 \\
{[0.00419]}\end{array}$ & $\begin{array}{l}0.0330^{* * *} \\
{[0.00780]}\end{array}$ \\
\hline Investigated PA & & & & & $\begin{array}{c}-0.0170^{* * *} \\
{[0.00639]}\end{array}$ & $\begin{array}{c}-0.0257^{* * *} \\
{[0.00754]}\end{array}$ & $\begin{array}{c}0.00372 \\
{[0.00461]}\end{array}$ & $\begin{array}{c}-0.0291^{* * *} \\
{[0.00598]}\end{array}$ \\
\hline Dep. Var. Mean & 0.222 & 0.222 & 0.222 & 0.222 & 0.222 & 0.222 & 0.0589 & 0.169 \\
\hline Observations & 206421 & 206421 & 206421 & 166768 & 166768 & 166768 & 166768 & 166768 \\
\hline R-sq & 0.325 & 0.257 & 0.321 & 0.210 & 0.210 & 0.211 & 0.131 & 0.196 \\
\hline Geog. FE & PA & PA & $\mathrm{PA}$ & Region & Region & Region & Region & Region \\
\hline
\end{tabular}

Note: The dependent variable is indicated on top of each column. DiscretProc denotes all negotiated procedures. DiscretProclown denotes negotiated procedures with fewer than the legally mandated number of bidders. DiscretCrit denotes scoring rule auctions. Discretion denotes auctions for which either DiscretProclown $=1$ or DiscretCrit $=1$. InvestigatedRUP is an indicator equal to 1 if the public official in charge of the auction has been investigated. InvestigatedPA is an indicator equal to 1 if any of the public officials in the PA have been investigated. All regressions include Year fixed effects, a linear control for reserve price (in log) Price and 5 dummies for different contract size thresholds (up to 100k, 100-150k, 150-300k, 300-500k, 500k-1mil, 1-1.5mil, over 1.5mil) as well as controls for contract characteristics: 4 dummies for category type (Civil Building, Roadworks, Specialized Works or Others), 1 dummy for whether the contract was awarded under urgency and 1 dummy for whether the object of the contract entailed maintenance. Robust standard errors clustered at the PA level are in parentheses. ${ }^{*} p<0.1,{ }^{* *} p<0.05,{ }^{* * *} p<0.01$.

Table 6: Auction-level regressions, outcomes

\begin{tabular}{|c|c|c|c|c|c|c|c|c|c|}
\hline & \multicolumn{3}{|c|}{ Delay (Asinh) } & \multicolumn{3}{|c|}{ Winning Discount } & \multicolumn{3}{|c|}{ Extra Cost } \\
\hline & $(1)$ & $(2)$ & $(3)$ & (4) & $(5)$ & (6) & (7) & $(8)$ & (9) \\
\hline Discretion & $\begin{array}{c}-0.142^{* * *} \\
{[0.0469]}\end{array}$ & & & $\begin{array}{c}-4.031^{* * *} \\
{[0.267]}\end{array}$ & & & $\begin{array}{l}-0.312 \\
{[0.282]}\end{array}$ & & \\
\hline $\operatorname{DiscretProc}_{\text {low } N}$ & & $\begin{array}{c}-0.259^{* * *} \\
{[0.0766]}\end{array}$ & $\begin{array}{l}-0.129^{*} \\
{[0.0756]}\end{array}$ & & $\begin{array}{c}-3.965^{* * *} \\
{[0.422]}\end{array}$ & $\begin{array}{c}-3.023^{* * *} \\
{[0.356]}\end{array}$ & & $\begin{array}{c}0.396 \\
{[0.509]}\end{array}$ & $\begin{array}{c}0.492 \\
{[0.520]}\end{array}$ \\
\hline DiscretCrit & & $\begin{array}{l}-0.0778 \\
{[0.0538]}\end{array}$ & $\begin{array}{l}-0.0837 \\
{[0.0535]}\end{array}$ & & $\begin{array}{c}-3.971^{* * *} \\
{[0.241]}\end{array}$ & $\begin{array}{c}-4.117^{* * *} \\
{[0.251]}\end{array}$ & & $\begin{array}{c}-0.640^{* *} \\
{[0.268]}\end{array}$ & $\begin{array}{c}-0.656^{* *} \\
{[0.270]}\end{array}$ \\
\hline $\operatorname{DiscretProc}_{h i g h N}$ & & & $\begin{array}{c}-0.340^{* * *} \\
{[0.0635]}\end{array}$ & & & $\begin{array}{c}-2.426^{* * *} \\
{[0.356]}\end{array}$ & & & $\begin{array}{l}-0.276 \\
{[0.215]}\end{array}$ \\
\hline Dep. Var. Mean & 3.296 & 3.296 & 3.296 & 18.11 & 18.11 & 18.11 & 7.035 & 7.035 & 7.035 \\
\hline Observations & 107067 & 107067 & 107067 & 191053 & 191053 & 191053 & 81439 & 81439 & 81439 \\
\hline R-sq & 0.250 & 0.250 & 0.251 & 0.443 & 0.444 & 0.448 & 0.219 & 0.219 & 0.219 \\
\hline
\end{tabular}

Note: The dependent variable is indicated at the top of each column. Delay is the inverse hyperbolic sine transformation of the number of days between the expected contractual duration and the effective total completion time. Winning Discount is the final price of the winning bid expressed as a discount over the reserve price (Discount) and ExtraCost represents excess completion costs, calculated as the difference between the final price and awarding price, over the initial reserve price. DiscretProchighN denotes negotiated procedures with at least the the legally mandated number of bidders.

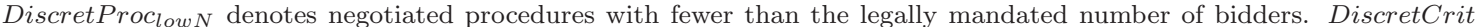
denotes scoring rule auctions. Discretion denotes auctions for which either DiscretProc low $_{N}=1$ or DiscretCrit=1. All regressions include PA and Year fixed effects, a linear control for reserve price (in log) Price and 5 dummies for different contract size thresholds (up to $100 \mathrm{k}, 100-150 \mathrm{k}, 150-300 \mathrm{k}, 300-500 \mathrm{k}, 500 \mathrm{k}-1 \mathrm{mil}, 1-1.5 \mathrm{mil}$, over $1.5 \mathrm{mil}$ ) as well as controls for contract characteristics: 4 dummies for category type (Civil Building, Roadworks, Specialized Works or Others), 1 dummy for whether the contract was awarded under urgency and 1 dummy for whether the object of the contract entailed maintenance. Robust standard errors clustered at the PA level are in parentheses. ${ }^{*} p<0.1,{ }^{* *} p<0.05,{ }^{* * *} p<0.01$. 


\section{Appendix: For Online Publication Only}

\section{A Additional Tables and Figures}

Figure A1: Regulatory Constraints and the Procurement Audit System

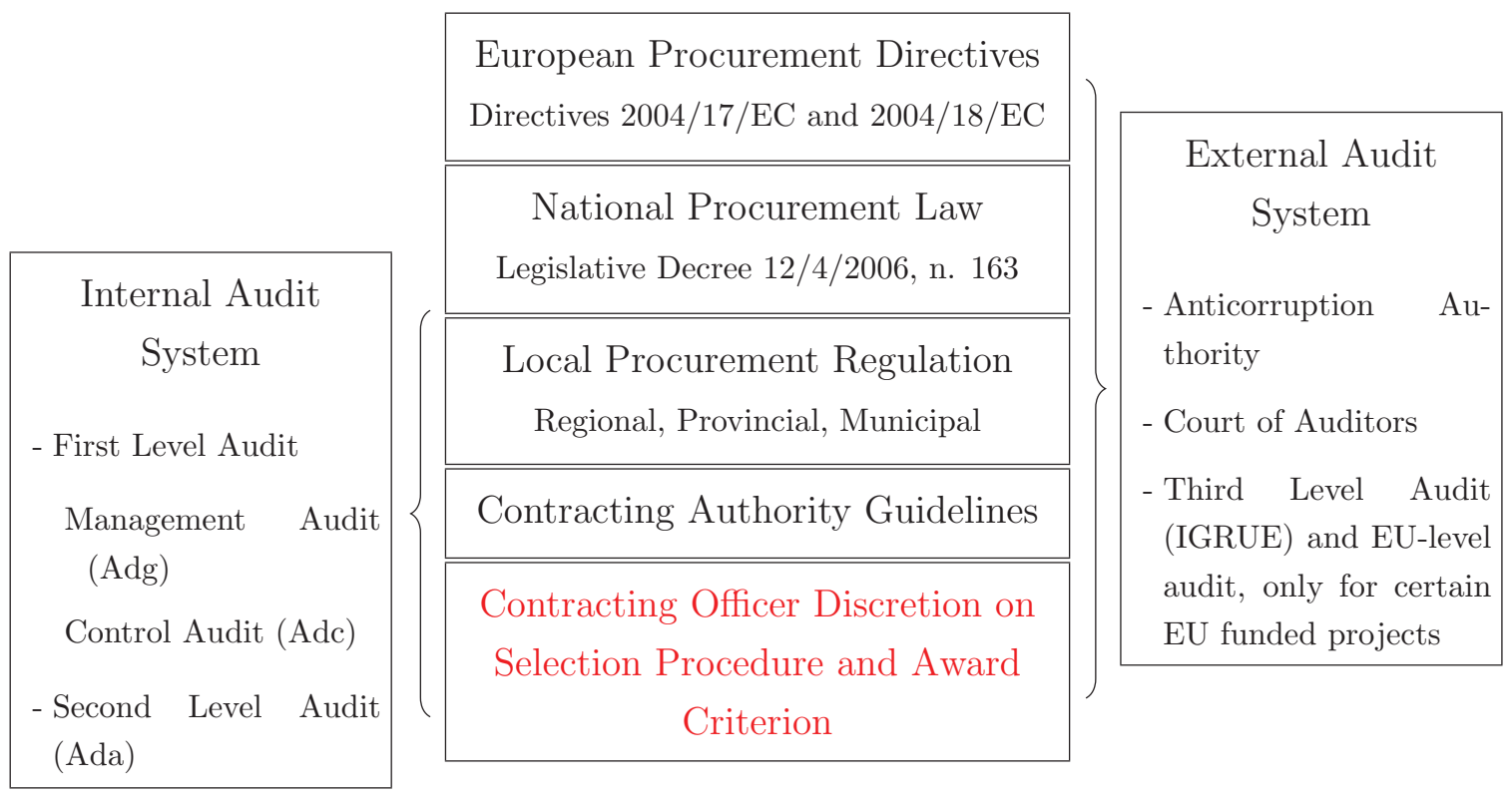

Note: The figure illustrates the set of regulatory constraints and audit oversight, subject to which a contracting officer exercises discretion over the supplier selection procedure and contract awarding criterion. At any point in time, the exact set of regulations and audit processes applicable depend on the contract reserve price, job characteristics, source of project funding, and the identity of the contracting authority. The system has changed over time, but for most of the contracts in our sample, the relevant regulations are the European Procurement Directives 2004/17 and 2004/18 and Italian procurement law (L.D. 163/2006). For the typical contract, the audit process has two levels and is also subject to scrutiny by external auditors. When the project is at least in part funded by the EU, there is a third audit level conducted by the regional offices of the Ministry of the Treasury (IGRUE) and, possibly, further levels of European audits as well. 
Figure A2: The Investigation Process

One of the country's four police forces is notified of potential crimes by private citizens or public officials

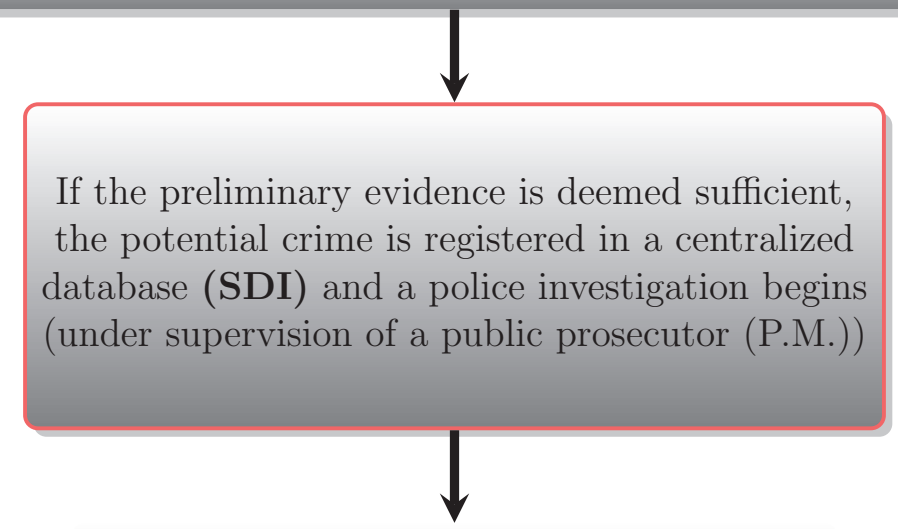

If there are suitable elements to proceed, the P.M. requests the supervising judge for Preliminary Inquiries (G.I.P.) to refer the case to the court for a preliminary hearing before a judge (G.U.P.)

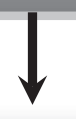

The defendant is notified of preliminary hearings and has the right to be defended by a lawyer

The G.U.P. considers the arguments brought by the prosecutor and defendants lawyer and de-

cides whether to dismiss or begin a formal criminal trial

The case is brought before the First Instance Court

Note: The figure shows the various steps in the investigation process in Italy. Our data comes from the second step, highlighted in red. 
Figure A3: Distribution of number of bidders, by type of awarding criterion

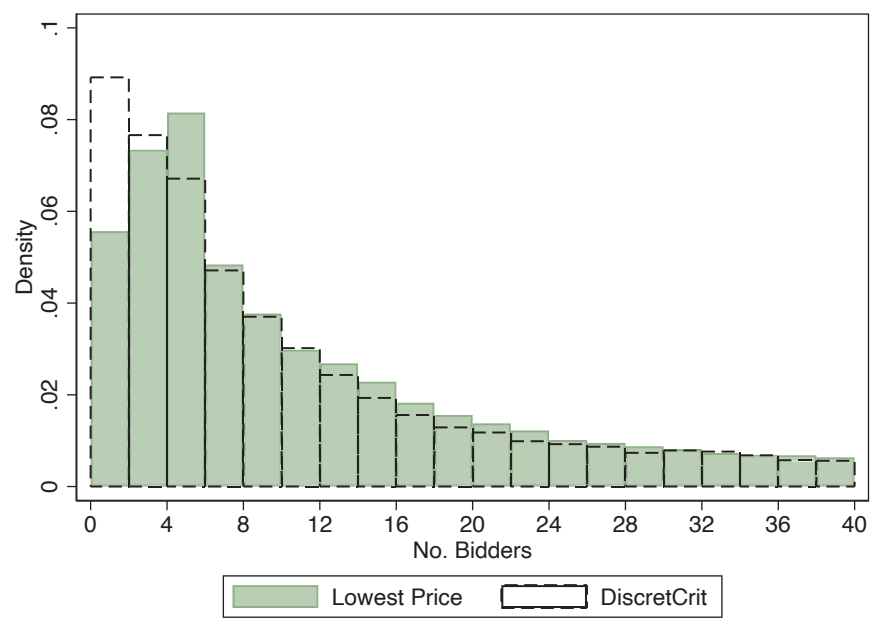

Note: The figure represents two histograms of the number of bidders, for auctions using lowest price or scoring rule (DiscretCrit) as awarding criteria. For ease of visualization, the plot is limited to auctions with up to 40 bidders, which represent $80 \%$ of auctions in our sample. 
Figure A4: Regression discontinuity plots
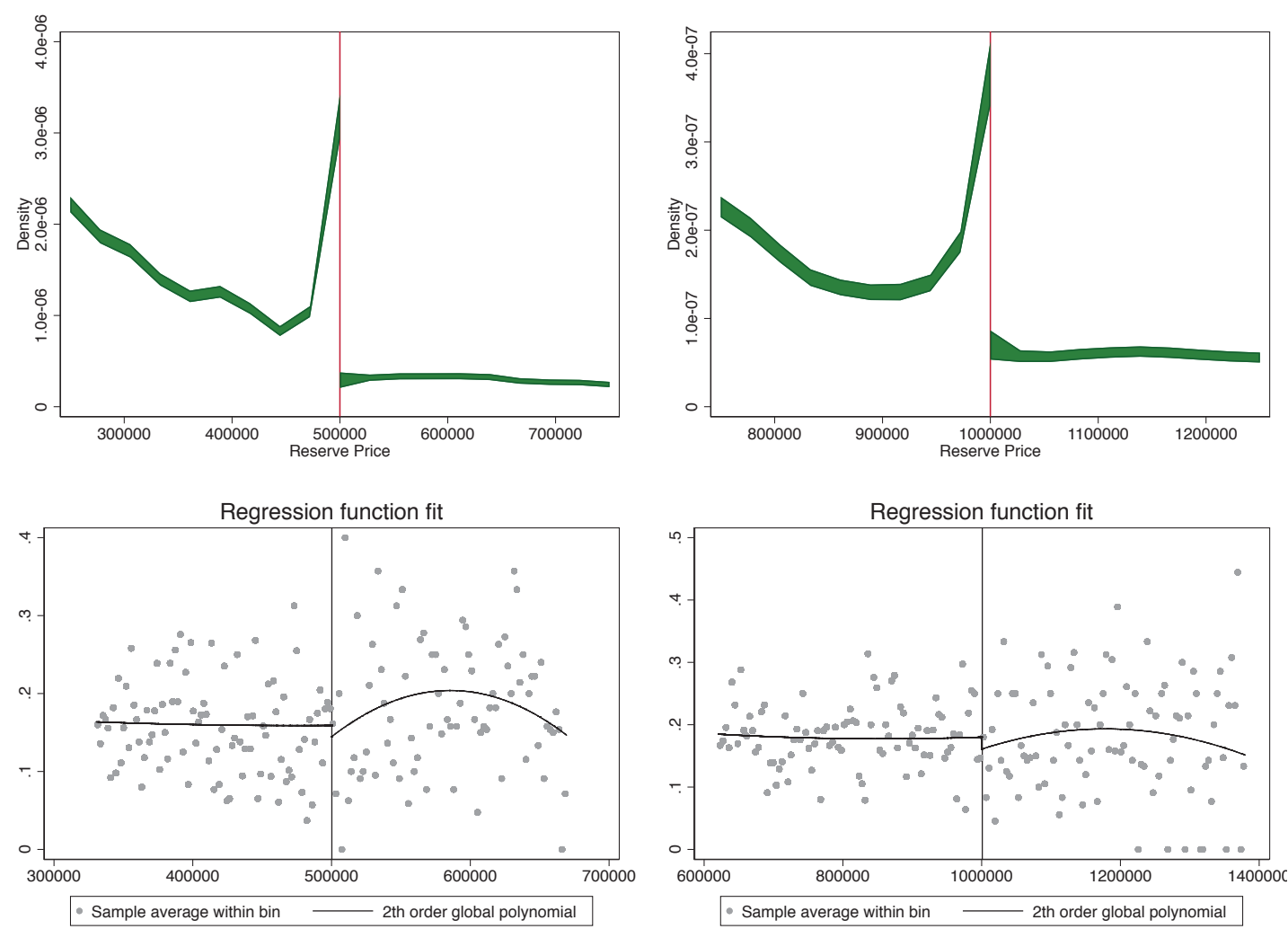

Note: These graphs depict the results of our analysis using a Regression Discontinuity Design. The top panels display the density of contracts with reserve price around the $€ 500,000$ and $€ 1,000,000$ cutoffs, respectively. The green bands depict confidence intervals for the of the estimated density function. The bottom panels display the average fraction of contracts awarded to investigated firms across equally-sized bins of the reserve price, and fitted polynomials functions on each side of the cutoff. All estimates are performed using optimal bandwidth selection procedure by Cattaneo et al. [2019]. 
Table A1: Summary Statistics by Sector and RUP type

\begin{tabular}{lcc}
\hline & $(1)$ & $(2)$ \\
& Roads & Buildings \\
\hline investigated Firm & 0.192 & 0.127 \\
& $(0.394)$ & $(0.333)$ \\
Investigated RUP & 0.113 & 0.103 \\
& $(0.316)$ & $(0.303)$ \\
Discretion & 0.238 & 0.282 \\
& $(0.426)$ & $(0.450)$ \\
Discr. Auction, Investigated RUP & 0.221 & 0.287 \\
& $(0.415)$ & $(0.452)$ \\
Discr. Auction, clear RUP & 0.243 & 0.285 \\
& $(0.429)$ & $(0.452)$ \\
& & $(2)$ \\
& $(1)$ & Lot \\
Investigated RUP & Local RUP & 0.112 \\
& 0.127 & $(0.315)$ \\
investigated Firm & $(0.333)$ & 0.159 \\
local Firm & 0.170 & $(0.366)$ \\
& $(0.376)$ & 0.122 \\
Discretion & 0.226 & $(0.327)$ \\
Discr. Auction, Investigated RUP & $(0.419)$ & 0.245 \\
& 0.185 & $(0.430)$ \\
Discr. Auction, clear RUP & $(0.389)$ & 0.252 \\
& 0.160 & $(0.434)$ \\
& $(0.366)$ & 0.245 \\
& 0.189 & $(0.430)$ \\
\hline
\end{tabular}

Note: InvestigatedRUP is an indicator equal to 1 if the public official in charge of the auction has been investigated. InvestigatedWinner is an indicator equal to 1 if the firm winning the auction has been investigated. Discr.Auction denotes auctions for which either a discretionary procedure with fewer than the legally mandated number of bidders (DiscretProc lowN) or a discretionary criterion (DiscretCrit) has been used to award the auction. 
Table A2: Auction-level regressions, investigated winner - Restrictive definition

\begin{tabular}{|c|c|c|c|c|c|c|c|c|c|c|}
\hline & \multicolumn{5}{|c|}{ all } & \multicolumn{5}{|c|}{ cities } \\
\hline & (1) & $(2)$ & (3) & (4) & $(5)$ & (6) & (7) & (8) & (9) & $(10)$ \\
\hline DiscretCrit & $\begin{array}{c}0.00983^{* * *} \\
{[0.00275]}\end{array}$ & & $\begin{array}{l}0.0107^{* * *} \\
{[0.00281]}\end{array}$ & $\begin{array}{l}0.0109^{* * *} \\
{[0.00281]}\end{array}$ & & $\begin{array}{l}0.0143^{* * *} \\
{[0.00324]}\end{array}$ & & $\begin{array}{l}0.0149^{* * *} \\
{[0.00326]}\end{array}$ & $\begin{array}{l}0.0150^{* * *} \\
{[0.00326]}\end{array}$ & \\
\hline $\operatorname{DiscretProc}_{\text {low }}$ & & $\begin{array}{l}0.0181^{* * *} \\
{[0.00408]}\end{array}$ & $\begin{array}{l}\text { * } 0.0193^{* * *} \\
{[0.00418]}\end{array}$ & $\begin{array}{l}0.0163^{* * *} \\
{[0.00426]}\end{array}$ & & & $\begin{array}{c}0.00979^{* * *} \\
{[0.00345]}\end{array}$ & $\begin{array}{l}0.0117^{* * *} \\
{[0.00352]}\end{array}$ & $\begin{array}{l}0.0110^{* * *} \\
{[0.00364]}\end{array}$ & \\
\hline $\operatorname{DiscretProc}_{h i g h N}$ & & & & $\begin{array}{c}0.00773^{* * *} \\
{[0.00230]}\end{array}$ & $\begin{array}{c}0.00864^{* * *} \\
{[0.00228]}\end{array}$ & & & & $\begin{array}{c}0.00209 \\
{[0.00287]}\end{array}$ & $\begin{array}{c}0.00180 \\
{[0.00277]}\end{array}$ \\
\hline Discretion & & & & & $\begin{array}{l}0.0119^{* * *} \\
{[0.00253]}\end{array}$ & & & & & $\begin{array}{l}0.0148^{* * *} \\
{[0.00281]}\end{array}$ \\
\hline Dep. Var. Mean & 0.170 & 0.170 & 0.170 & 0.170 & 0.170 & 0.170 & 0.170 & 0.170 & 0.170 & 0.170 \\
\hline Observations & 199089 & 199089 & 199089 & 199089 & 199089 & 107994 & 107994 & 107994 & 107994 & 107994 \\
\hline R-sq & 0.103 & 0.103 & 0.103 & 0.104 & 0.103 & 0.112 & 0.112 & 0.112 & 0.112 & 0.112 \\
\hline
\end{tabular}

Note: In all specifications, the dependent variable is an indicator equal to 1 if an investigated firm is awarded the contract. In this table, we restrict the definition of investigated firms to those investigated for (i) corruption, malfeasance and embezzlement or (ii) abuse of power and undue influence, (i.e., we do not include in our definition those investigated for violations in public auctions. DiscretProc denotes negotiated procedures. DiscretProc ${ }_{l o w N}$ denotes negotiated procedures with fewer than the legally mandated number of bidders. DiscretCrit denotes scoring rule auctions. Discretion denotes auctions for which either DiscretProc $l o w N=1$ or DiscretCrit=1. All regressions include PA and Year fixed effects, a linear control for reserve price (in log) price and 5 dummies for different contract size thresholds (up to $100 \mathrm{k}, 100-150 \mathrm{k}, 150-300 \mathrm{k}$, 300-500k, 500k-1mil, 1-1.5mil, over 1.5mil) as well as controls for contract characteristics: 4 dummies for category type (Civil Building, Roadworks, Specialized Works or Others), 1 dummy for whether the contract was awarded under urgency and 1 dummy for whether the object of the contract entailed maintenance. Robust standard errors clustered at the PA level are in parentheses. ${ }^{*} p<0.1,{ }^{* *} p<0.05,{ }^{* * *} p<0.01$.

Table A3: Auction-level regressions, investigated winner - Broad definition

\begin{tabular}{|c|c|c|c|c|c|c|c|c|c|c|}
\hline & \multicolumn{5}{|c|}{ all } & \multicolumn{5}{|c|}{ cities } \\
\hline & (1) & $(2)$ & (3) & (4) & $(5)$ & (6) & (7) & (8) & (9) & $(10)$ \\
\hline DiscretCrit & $\begin{array}{l}0.0170^{* * *} \\
{[0.00369]}\end{array}$ & & $\begin{array}{l}0.0181^{* * *} \\
{[0.00371]}\end{array}$ & $\begin{array}{l}0.0182^{* * *} \\
{[0.00372]}\end{array}$ & & $\begin{array}{l}0.0203^{* * *} \\
{[0.00470]}\end{array}$ & & $\begin{array}{l}0.0210^{* * *} \\
{[0.00470]}\end{array}$ & $\begin{array}{l}0.0212^{* * *} \\
{[0.00470]}\end{array}$ & \\
\hline $\operatorname{DiscretProc}_{\text {lowN }}$ & & $\begin{array}{l}0.0212^{* * *} \\
{[0.00557]}\end{array}$ & $\begin{array}{l}0.0231^{* * *} \\
{[0.00559]}\end{array}$ & $\begin{array}{l}0.0206^{* * *} \\
{[0.00588]}\end{array}$ & & & $\begin{array}{c}0.0125^{*} \\
{[0.00714]}\end{array}$ & $\begin{array}{c}0.0152^{* *} \\
{[0.00711]}\end{array}$ & $\begin{array}{l}0.0143^{* *} \\
{[0.00723]}\end{array}$ & \\
\hline $\operatorname{DiscretProc}_{h i g h N}$ & & & & $\begin{array}{l}0.00650^{*} \\
{[0.00378]}\end{array}$ & $\begin{array}{l}0.00719^{* *} \\
{[0.00362]}\end{array}$ & & & & $\begin{array}{c}0.00278 \\
{[0.00504]}\end{array}$ & $\begin{array}{c}0.00224 \\
{[0.00496]}\end{array}$ \\
\hline Discretion & & & & & $\begin{array}{l}0.0180^{* * *} \\
{[0.00337]}\end{array}$ & & & & & $\begin{array}{l}0.0201^{* * *} \\
{[0.00424]}\end{array}$ \\
\hline Dep. Var. Mean & 0.170 & 0.170 & 0.170 & 0.170 & 0.170 & 0.170 & 0.170 & 0.170 & 0.170 & 0.170 \\
\hline Observations & 199089 & 199089 & 199089 & 199089 & 199089 & 107994 & 107994 & 107994 & 107994 & 107994 \\
\hline R-sq & 0.138 & 0.138 & 0.138 & 0.138 & 0.138 & 0.148 & 0.148 & 0.148 & 0.148 & 0.148 \\
\hline
\end{tabular}

Note: In all specifications, the dependent variable is an indicator equal to 1 if an investigated firm is awarded the contract. In this table, we extend the definition of investigated firms to include firms investigated for waste management crimes. DiscretProc denotes negotiated procedures. DiscretProc ${ }_{l o w N}$ denotes negotiated procedures with fewer than the legally mandated number of bidders. DiscretCrit denotes scoring rule auctions. Discretion denotes auctions for which either DiscretProc $\operatorname{lowN}_{N}=1$ or DiscretCrit=1. All regressions include PA and Year fixed effects, a linear control for reserve price (in log) Price and 5 dummies for different contract size thresholds (up to 100k, 100-150k, 150-300k, 300-500k, 500k-1mil, 1$1.5 \mathrm{mil}$, over 1.5mil) as well as controls for contract characteristics: 4 dummies for category type (Civil Building, Roadworks, Specialized Works or Others), 1 dummy for whether the contract was awarded under urgency and 1 dummy for whether the object of the contract entailed maintenance. Robust standard errors clustered at the PA level are in parentheses. ${ }^{*} p<0.1,{ }^{* *} p<0.05,{ }^{* * *} p<0.01$. 
Table A4: Auction-level regressions, Convicted Winner

\begin{tabular}{|c|c|c|c|c|c|c|c|c|c|c|}
\hline & \multicolumn{5}{|c|}{ all } & \multicolumn{5}{|c|}{ cities } \\
\hline & $(1)$ & $(2)$ & (3) & (4) & $(5)$ & (6) & $(7)$ & (8) & (9) & $(10)$ \\
\hline DiscretCrit & $\begin{array}{c}0.00190 \\
{[0.00205]}\end{array}$ & & $\begin{array}{c}0.00205 \\
{[0.00209]}\end{array}$ & $\begin{array}{c}0.00210 \\
{[0.00212]}\end{array}$ & & $\begin{array}{c}0.00237 \\
{[0.00336]}\end{array}$ & & $\begin{array}{c}0.00252 \\
{[0.00346]}\end{array}$ & $\begin{array}{c}0.00265 \\
{[0.00357]}\end{array}$ & \\
\hline $\operatorname{DiscretProc}_{\text {lowN }}$ & & $\begin{array}{l}0.00305^{*} \\
{[0.00160]}\end{array}$ & $\begin{array}{l}0.00327^{*} \\
{[0.00173]}\end{array}$ & $\begin{array}{l}0.00251^{*} \\
{[0.00144]}\end{array}$ & & & $\begin{array}{c}0.00281 \\
{[0.00234]}\end{array}$ & $\begin{array}{c}0.00313 \\
{[0.00266]}\end{array}$ & $\begin{array}{c}0.00220 \\
{[0.00201]}\end{array}$ & \\
\hline DiscretProc $_{h i g h N}$ & & & & $\begin{array}{c}0.00199 \\
{[0.00158]}\end{array}$ & $\begin{array}{c}0.00208 \\
{[0.00147]}\end{array}$ & & & & $\begin{array}{c}0.00269 \\
{[0.00282]}\end{array}$ & $\begin{array}{c}0.00268 \\
{[0.00261]}\end{array}$ \\
\hline Discretion & & & & & $\begin{array}{c}0.00221 \\
{[0.00188]}\end{array}$ & & & & & $\begin{array}{c}0.00255 \\
{[0.00321]}\end{array}$ \\
\hline Dep. Var. Mean & 0.0169 & 0.0169 & 0.0169 & 0.0169 & 0.0169 & 0.0169 & 0.0169 & 0.170 & 0.0169 & 0.0169 \\
\hline Observations & 199089 & 199089 & 199089 & 199089 & 199089 & 107994 & 107994 & 107994 & 107994 & 107994 \\
\hline R-sq & 0.129 & 0.129 & 0.129 & 0.129 & 0.129 & 0.157 & 0.157 & 0.157 & 0.157 & 0.157 \\
\hline
\end{tabular}

Note: In this table, in all specifications, the dependent variable is an indicator equal to 1 if a firm ever convicted for corruption is awarded the contract. DiscretProc denotes negotiated procedures. DiscretProc low $_{\text {N }}$ denotes negotiated procedures with fewer than the legally mandated number of bidders. DiscretCrit denotes scoring rule auctions. Discretion denotes auctions for which either DiscretProc ${ }_{l o w N}=1$ or DiscretCrit=1. All regressions include PA and Year fixed effects, a linear control for reserve price (in log) Price and 5 dummies for different contract size thresholds (up to 100k, 100-150k, 150-300k, 300-500k, 500k-1mil, 1-1.5mil, over 1.5mil) as well as controls for contract characteristics: 4 dummies for category type (Civil Building, Roadworks, Specialized Works or Others), 1 dummy for whether the contract was awarded under urgency and 1 dummy for whether the object of the contract entailed maintenance. Robust standard errors clustered at the PA level are in parentheses. ${ }^{*} p<0.1,{ }^{* *} p<0.05,{ }^{* * *} p<0.01$.

Table A5: Auction-level regressions, PA X Year fixed effects

\begin{tabular}{|c|c|c|c|c|c|c|c|c|c|c|}
\hline & \multicolumn{5}{|c|}{ all } & \multicolumn{5}{|c|}{ cities } \\
\hline & $(1)$ & $(2)$ & $(3)$ & $(4)$ & $(5)$ & $(6)$ & $(7)$ & $(8)$ & (9) & $(10)$ \\
\hline DiscretCrit & $\begin{array}{l}0.00752^{*} \\
{[0.00455]}\end{array}$ & & $\begin{array}{l}0.00791^{*} \\
{[0.00456]}\end{array}$ & $\begin{array}{l}0.00795^{*} \\
{[0.00456]}\end{array}$ & & $\begin{array}{l}0.0186^{* * *} \\
{[0.00647]}\end{array}$ & & $\begin{array}{l}0.0188^{* * *} \\
{[0.00648]}\end{array}$ & $\begin{array}{l}0.0187^{* * *} \\
{[0.00647]}\end{array}$ & \\
\hline DiscretProc $_{\text {low } N}$ & & $\begin{array}{l}0.0236^{* * *} \\
{[0.00572]}\end{array}$ & $\begin{array}{l}0.0239^{* * *} \\
{[0.00575]}\end{array}$ & $\begin{array}{l}0.0224^{* * *} \\
{[0.00602]}\end{array}$ & & & $\begin{array}{l}0.0176^{* *} \\
{[0.00760]}\end{array}$ & $\begin{array}{c}0.0180^{* *} \\
{[0.00760]}\end{array}$ & $\begin{array}{l}0.0196^{* * *} \\
{[0.00758]}\end{array}$ & \\
\hline DiscretProc $_{h i g h N}$ & & & & $\begin{array}{c}0.00375 \\
{[0.00415]}\end{array}$ & $\begin{array}{c}0.00559 \\
{[0.00407]}\end{array}$ & & & & $\begin{array}{l}-0.00476 \\
{[0.00636]}\end{array}$ & $\begin{array}{l}-0.00451 \\
{[0.00633]}\end{array}$ \\
\hline Discretion & & & & & $\begin{array}{l}0.0116^{* * *} \\
{[0.00410]}\end{array}$ & & & & & $\begin{array}{l}0.0206^{* * *} \\
{[0.00538]}\end{array}$ \\
\hline Dep. Var. Mean & 0.170 & 0.170 & 0.170 & 0.170 & 0.170 & 0.170 & 0.170 & 0.170 & 0.170 & 0.170 \\
\hline Observations & 170210 & 170210 & 170210 & 170210 & 170210 & 86195 & 86195 & 86195 & 86195 & 86195 \\
\hline R-sq & 0.241 & 0.241 & 0.241 & 0.241 & 0.241 & 0.289 & 0.289 & 0.289 & 0.289 & 0.289 \\
\hline
\end{tabular}

Note: In all specifications, the dependent variable is an indicator equal to 1 if an investigated winner is awarded the contract. DiscretProc denotes negotiated procedures. DiscretProc ${ }_{l o w}$ denotes negotiated procedures with fewer than the legally mandated number of bidders. DiscretCrit denotes scoring rule auctions. Discretion denotes auctions for which either DiscretProc ${ }_{l o w n}=1$ or DiscretCrit=1. All regressions include PA*Year fixed effects, a linear control for reserve price (in log) price and 5 dummies for different contract size thresholds (up to 100k, 100-150k, 150-300k, 300-500k, 500k-1mil, 1$1.5 \mathrm{mil}$, over 1.5mil) as well as controls for contract characteristics: 4 dummies for category type (Civil Building, Roadworks, Specialized Works or Others), 1 dummy for whether the contract was awarded under Urgency and 1 dummy for whether the object of the contract entailed maintenance. Robust standard errors clustered at the PA level are in parentheses. ${ }^{*} p<0.1,{ }^{* *} p<0.05,{ }^{* * *} p<0.01$. 
Table A6: Auction-level regressions, investigated winner, controlling for connections

\begin{tabular}{|c|c|c|c|c|c|c|c|c|c|c|}
\hline & \multicolumn{5}{|c|}{ all } & \multicolumn{5}{|c|}{ cities } \\
\hline & (1) & $(2)$ & (3) & (4) & $(5)$ & (6) & $(7)$ & (8) & (9) & (10) \\
\hline DiscretCrit & $\begin{array}{c}0.00853^{* * *} \\
{[0.00318]}\end{array}$ & & $\begin{array}{c}0.00937^{* * *} \\
{[0.00321]}\end{array}$ & $\begin{array}{c}0.00934^{* * *} \\
{[0.00321]}\end{array}$ & & $\begin{array}{l}0.0162^{* * *} \\
{[0.00391]}\end{array}$ & & $\begin{array}{l}0.0168^{* * *} \\
{[0.00392]}\end{array}$ & $\begin{array}{l}\text { * } 0.0166^{* * *} \\
{[0.00393]}\end{array}$ & \\
\hline Connected & $\begin{array}{c}0.140^{* * *} \\
{[0.00445]}\end{array}$ & $\begin{array}{c}0.140^{* * *} \\
{[0.00445]}\end{array}$ & $\begin{array}{c}0.140^{* * *} \\
{[0.00444]}\end{array}$ & $\begin{array}{c}0.140^{* * *} \\
{[0.00444]}\end{array}$ & $\begin{array}{c}0.140^{* * *} \\
{[0.00444]}\end{array}$ & $\begin{array}{c}0.129^{* * *} \\
{[0.00552]}\end{array}$ & $\begin{array}{c}0.129^{* * *} \\
{[0.00553]}\end{array}$ & $\begin{array}{c}0.129^{* * *} \\
{[0.00552]}\end{array}$ & $\begin{array}{c}0.129^{* * *} \\
{[0.00551]}\end{array}$ & $\begin{array}{c}0.129^{* * *} \\
{[0.00551]}\end{array}$ \\
\hline $\operatorname{DiscretProc}_{\text {low } N}$ & & $\begin{array}{l}0.0176^{* * *} \\
{[0.00481]}\end{array}$ & $\begin{array}{l}0.0186^{* * *} \\
{[0.00485]}\end{array}$ & $\begin{array}{l}0.0189^{* * *} \\
{[0.00494]}\end{array}$ & & & $\begin{array}{c}0.0101^{*} \\
{[0.00600]}\end{array}$ & $\begin{array}{c}0.0123^{* *} \\
{[0.00598]}\end{array}$ & $\begin{array}{c}0.0140^{* *} \\
{[0.00589]}\end{array}$ & \\
\hline DiscretProc $_{h i g h N}$ & & & & $\begin{array}{l}-0.00102 \\
{[0.00312]}\end{array}$ & $\begin{array}{l}0.000425 \\
{[0.00310]}\end{array}$ & & & & $\begin{array}{l}-0.00501 \\
{[0.00418]}\end{array}$ & $\begin{array}{l}-0.00511 \\
{[0.00419]}\end{array}$ \\
\hline Discretion & & & & & $\begin{array}{l}0.0110^{* * *} \\
{[0.00295]}\end{array}$ & & & & & $\begin{array}{l}0.0167^{* * *} \\
{[0.00362]}\end{array}$ \\
\hline Constant & $\begin{array}{c}-0.377^{* * *} \\
{[0.0583]}\end{array}$ & $\begin{array}{c}-0.383^{* * *} \\
{[0.0579]}\end{array}$ & $\begin{array}{c}-0.380^{* * *} \\
{[0.0581]}\end{array}$ & $\begin{array}{c}-0.379^{* * *} \\
{[0.0589]}\end{array}$ & $\begin{array}{c}-0.379^{* * *} \\
{[0.0589]}\end{array}$ & $\begin{array}{c}-0.203^{* * *} \\
{[0.0748]}\end{array}$ & $\begin{array}{c}-0.209^{* * *} \\
{[0.0753]}\end{array}$ & $\begin{array}{c}-0.204^{* * *} \\
{[0.0750]}\end{array}$ & $\begin{array}{c}-0.200^{* * *} \\
{[0.0755]}\end{array}$ & $\begin{array}{r}-0.201^{* * *} \\
{[0.0754]}\end{array}$ \\
\hline Dep. Var. Mean & 0.170 & 0.170 & 0.170 & 0.170 & 0.170 & 0.170 & 0.170 & 0.170 & 0.170 & 0.170 \\
\hline Observations & 199089 & 199089 & 199089 & 199089 & 199089 & 107994 & 107994 & 107994 & 107994 & 107994 \\
\hline R-sq & 0.143 & 0.143 & 0.143 & 0.143 & 0.143 & 0.151 & 0.151 & 0.151 & 0.151 & 0.151 \\
\hline
\end{tabular}

Note: In all specifications, the dependent variable is an indicator equal to 1 if an investigated firm is awarded the contract. DiscretProchighN denotes negotiated procedures with at least the legally mandated number of bidders. DiscretProclowN denotes negotiated procedures with fewer than the legally mandated number of bidders. DiscretCrit denotes scoring rule auctions. Discretion denotes auctions for which either DiscretProc ${ }_{\text {low } N}=1$ or DiscretCrit $=1$. All regressions include PA and Year fixed effects, a linear control for reserve price (in log) price and 5 dummies for different contract size thresholds (up to $100 \mathrm{k}, 100-150 \mathrm{k}, 150-300 \mathrm{k}, 300-500 \mathrm{k}, 500 \mathrm{k}-1 \mathrm{mil}, 1-1.5 \mathrm{mil}$, over 1.5mil) as well as controls for contract characteristics: 4 dummies for category type (Civil Building, Roadworks, Specialized Works or Others), 1 dummy for whether the contract was awarded under urgency and 1 dummy for whether the object of the contract entailed maintenance. Robust standard errors clustered at the PA level are in parentheses. ${ }^{*} p<0.1,{ }^{* *} p<0.05,{ }^{* * *} p<0.01$.

Table A7: Bidder-level regressions, participants' pool

\begin{tabular}{|c|c|c|c|c|c|c|c|c|c|c|}
\hline & \multicolumn{5}{|c|}{ participant } & \multicolumn{5}{|c|}{ auction } \\
\hline & (1) & $(2)$ & (3) & (4) & (5) & (6) & (7) & (8) & (9) & (10) \\
\hline DiscretCrit & $\begin{array}{c}0.00248 \\
{[0.00292]}\end{array}$ & & $\begin{array}{c}0.00240 \\
{[0.00292]}\end{array}$ & $\begin{array}{c}0.00232 \\
{[0.00292]}\end{array}$ & & $\begin{array}{c}0.0199^{* *} \\
{[0.00924]}\end{array}$ & & $\begin{array}{c}0.0198^{* *} \\
{[0.00923]}\end{array}$ & $\begin{array}{l}0.0197^{* *} \\
{[0.00930]}\end{array}$ & \\
\hline $\operatorname{DiscretProc}_{\text {low } N}$ & & $\begin{array}{l}0.0125^{* *} \\
{[0.00533]}\end{array}$ & $\begin{array}{l}0.0125^{* *} \\
{[0.00533]}\end{array}$ & $\begin{array}{l}0.0143^{* * *} \\
{[0.00538]}\end{array}$ & & & $\begin{array}{l}0.0221^{* *} \\
{[0.00896]}\end{array}$ & $\begin{array}{l}0.0220^{* *} \\
{[0.00896]}\end{array}$ & $\begin{array}{c}0.0221^{* *} \\
{[0.00912]}\end{array}$ & \\
\hline $\operatorname{DiscretProc}_{h i g h N}$ & & & & $\begin{array}{l}-0.00364 \\
{[0.00392]}\end{array}$ & $\begin{array}{l}-0.00282 \\
{[0.00392]}\end{array}$ & & & & $\begin{array}{c}-0.000338 \\
{[0.00801]}\end{array}$ & $\begin{array}{l}0.000571 \\
{[0.00774]}\end{array}$ \\
\hline Discretion & & & & & $\begin{array}{c}0.00114 \\
{[0.00228]}\end{array}$ & & & & & $\begin{array}{l}0.0223^{* * *} \\
{[0.00738]}\end{array}$ \\
\hline Dep. Var. Mean & 0.163 & 0.163 & 0.163 & 0.163 & 0.163 & 0.161 & 0.161 & 0.161 & 0.161 & 0.161 \\
\hline Observations & 462821 & 462821 & 462821 & 462821 & 462821 & 24197 & 24197 & 24197 & 24197 & 24197 \\
\hline R-sq & 0.0562 & 0.0563 & 0.0563 & 0.0563 & 0.0562 & 0.223 & 0.223 & 0.223 & 0.223 & 0.223 \\
\hline
\end{tabular}

Note: In columns 1-5, the dependent variable is an indicator equal to 1 if an investigated firm participates in the auction. The unit of observation is the auction participant, so we have multiple observation per auction. Columns 6-10 replicate columns 6-10 of Table 4, but restricts the sample to auctions for which we have information on the participants. Across all columns, we restrict attention to contracts awarded by municipal councils. DiscretProc denotes negotiated procedures. DiscretProc $_{\text {low } N}$ denotes negotiated procedures with fewer than the legally mandated number of bidders. DiscretCrit denotes scoring rule auctions. Discretion denotes auctions for which either DiscretProc ${ }_{l o w n}=1$ or DiscretCrit=1. All regressions include controls for participant firms' characteristics, and in particular firm net worth, firm size, profits, operating margin, negative operating margin dummy, change in operating margin. Regressions also include PA and Year fixed effects, a linear control for reserve price (in log) price and 5 dummies for different contract size thresholds (up to 100k, 100-150k, 150-300k, 300-500k, 500k-1mil, 1-1.5mil, over 1.5mil) as well as controls for contract characteristics: 4 dummies for category type (Civil Building, Roadworks, Specialized Works or Others), 1 dummy for whether the contract was awarded under urgency and 1 dummy for whether the object of the contract entailed maintenance. Robust standard errors clustered at the PA level are in parentheses. ${ }^{*} p<0.1,{ }^{* *} p<0.05,{ }^{* * *} p<0.01$. 
Table A8: Auction-level regressions, investigated winner on investigated RUP

\begin{tabular}{|c|c|c|c|c|c|c|c|c|c|c|}
\hline & (1) & $(2)$ & $(3)$ & (4) & $(5)$ & (6) & $(7)$ & $(8)$ & (9) & (10) \\
\hline Investigated RUP & $\begin{array}{l}0.0095^{*} \\
{[0.0052]}\end{array}$ & $\begin{array}{l}0.0095^{*} \\
{[0.0052]}\end{array}$ & $\begin{array}{l}0.0092^{*} \\
{[0.0052]}\end{array}$ & $\begin{array}{l}0.0092^{*} \\
{[0.0052]}\end{array}$ & $\begin{array}{l}0.0093^{*} \\
{[0.0052]}\end{array}$ & $\begin{array}{l}0.0098^{*} \\
{[0.0052]}\end{array}$ & $\begin{array}{l}0.0096^{*} \\
{[0.0052]}\end{array}$ & $\begin{array}{l}0.0095^{*} \\
{[0.0052]}\end{array}$ & $\begin{array}{l}0.0097^{*} \\
{[0.0052]}\end{array}$ & $\begin{array}{c}0.0093^{*} \\
{[0.0052]}\end{array}$ \\
\hline DiscretCrit & $\begin{array}{c}0.0130^{* * *} \\
{[0.0033]}\end{array}$ & & $\begin{array}{c}0.0140^{* * *} \\
{[0.0033]}\end{array}$ & $\begin{array}{c}0.0141^{* * *} \\
{[0.0033]}\end{array}$ & & & $\begin{array}{c}0.0130^{* * *} \\
{[0.0033]}\end{array}$ & & & \\
\hline $\operatorname{DiscretProc}_{\text {lowN }}$ & & $\begin{array}{c}0.0215^{* * *} \\
{[0.0050]}\end{array}$ & $\begin{array}{c}0.0230^{* * *} \\
{[0.0050]}\end{array}$ & $\begin{array}{c}0.0224^{* * *} \\
{[0.0051]}\end{array}$ & & & & $\begin{array}{c}0.0215^{* * *} \\
{[0.0050]}\end{array}$ & & \\
\hline DiscretProc $_{h i g h N}$ & & & & $\begin{array}{c}0.0015 \\
{[0.0032]}\end{array}$ & $\begin{array}{c}0.0029 \\
{[0.0032]}\end{array}$ & & & & $\begin{array}{c}0.0043 \\
{[0.0032]}\end{array}$ & $\begin{array}{c}0.0029 \\
{[0.0032]}\end{array}$ \\
\hline Discretion & & & & & $\begin{array}{c}0.0154^{* * *} \\
{[0.0031]}\end{array}$ & & & & & $\begin{array}{c}0.0154^{* * *} \\
{[0.0031]}\end{array}$ \\
\hline PA FE & No & No & No & No & No & Yes & Yes & Yes & Yes & Yes \\
\hline Dep. Var. Mean & 0.170 & 0.170 & 0.170 & 0.170 & 0.170 & 0.170 & 0.170 & 0.170 & 0.170 & 0.170 \\
\hline Observations & 195158 & 195158 & 195158 & 195158 & 195158 & 195158 & 195158 & 195158 & 195158 & 195158 \\
\hline R-sq & 0.118 & 0.118 & 0.118 & 0.118 & 0.118 & 0.117 & 0.118 & 0.118 & 0.117 & 0.118 \\
\hline
\end{tabular}

Note: This table is the counterpart of Table 5 but including Investigated RUP among the regressors.

${ }^{*} p<0.1,{ }^{* *} p<0.05,{ }^{* * *} p<0.01$.

Table A9: Auction-level regressions, choice of procedure, province FE

\begin{tabular}{lcccccccc}
\hline & $(1)$ & $(2)$ & $(3)$ & $(4)$ & $(5)$ & $(6)$ & $(7)$ & $(8)$ \\
& Discretion & DiscretProc low N & DiscretCrit & Discretion & Discretion & Discretion & DiscretProc lown & DiscretCrit \\
\hline Investigated RUP & $0.0298^{* * *}$ & $0.00996^{* *}$ & $0.0210^{* * *}$ & $0.0207^{* * *}$ & & $0.0391^{* * *}$ & 0.00167 & $0.0381^{* * *}$ \\
& {$[0.00805]$} & {$[0.00402]$} & {$[0.00766]$} & {$[0.00731]$} & & {$[0.0100]$} & {$[0.00443]$} & {$[0.00888]$} \\
Investigated PA & & & & & $-0.0170^{* * *}$ & $-0.0297^{* * *}$ & 0.00124 & $-0.0318^{* * *}$ \\
& & & & & {$[0.00608]$} & {$[0.00786]$} & {$[0.00420]$} & {$[0.00589]$} \\
\hline Dep. Var. Mean & 0.222 & 0.222 & 0.222 & 0.222 & 0.222 & 0.222 & 0.0589 & 0.169 \\
Observations & 206421 & 206421 & 206421 & 110618 & 110618 & 110618 & 110618 & 110618 \\
R-sq & 0.325 & 0.257 & 0.321 & 0.228 & 0.228 & 0.229 & 0.143 & 0.212 \\
Geog. FE & PA & PA & PA & Province & Province & Province & Province & Province \\
\hline
\end{tabular}

Note: This Table is the counterpart of table 5 but using a finer partition for the geographic fixed effects, one for each of Italy's 110 provinces. DiscretProc denotes negotiated procedures. DiscretProc low $_{N}$ denotes negotiated procedures with fewer than the legally mandated number of bidders. DiscretCrit denotes scoring rule auctions. Discretion denotes auctions for which either DiscretProc ${ }_{l o w N}=1$ or DiscretCrit=1. Investigated RUP is an indicator equal to 1 if the public official in charge of the auction has been investigated. Investigated PA is an indicator equal to 1 if any of the public officials in the PA have been investigated. All regressions include Year fixed effects, a linear control for reserve price (in log) price and 5 dummies for different contract size thresholds (up to 100k, 100-150k, 150-300k, 300-500k, 500k-1mil, 1-1.5mil, over $1.5 \mathrm{mil}$ ) as well as controls for contract characteristics: 4 dummies for category type (Civil Building, Roadworks, Specialized Works or Others), 1 dummy for whether the contract was awarded under urgency and 1 dummy for whether the object of the contract entailed maintenance. Robust standard errors clustered at the PA level are in parentheses. ${ }^{*} p<0.1,{ }^{* *} p<0.05,{ }^{* * *} p<0.01$. 
Table A10: Auction-level regressions, choice of DiscretProc procedures

\begin{tabular}{lcccc}
\hline & $(1)$ & $(2)$ & $(3)$ & $(4)$ \\
\hline Investigated RUP & 0.000852 & 0.00873 & & 0.000846 \\
& {$[0.0101]$} & {$[0.00738]$} & & {$[0.00972]$} \\
Investigated PA & & & 0.0123 & 0.0120 \\
& & & {$[0.0101]$} & {$[0.0121]$} \\
\hline Dep. Var. Mean & 0.222 & 0.222 & 0.222 & 0.222 \\
Observations & 109511 & 110269 & 110269 & 110269 \\
R-sq & 0.574 & 0.500 & 0.500 & 0.500 \\
Geog. FE & $\mathrm{PA}$ & Region & Region & Region \\
\hline
\end{tabular}

Note: The dependent variable across columns is DiscretProc, which denotes all negotiated procedures. Investigated RUP is an indicator equal to 1 if the public official in charge of the auction has been investigated for corruption. Investigated PA is an indicator equal to 1 if at least one RUP in the PA has been investigated. All regressions include Year fixed effects, a linear control for reserve price (in log) price and 5 dummies for different contract size thresholds (up to 100k, 100-150k, 150-300k, 300-500k, 500k-1mil, 1-1.5mil, over 1.5mil) as well as controls for contract characteristics: 4 dummies for category type (Civil Building, Roadworks, Specialized Works or Others), 1 dummy for whether the contract was awarded under urgency and 1 dummy for whether the object of the contract entailed maintenance. Robust standard errors clustered at the PA level are in parentheses. ${ }^{*} p<0.1,{ }^{* *} p<0.05,{ }^{* * *} p<0.01$.

Table A11: Auction-level regressions, predicting the presence of outcomes' data

\begin{tabular}{|c|c|c|c|c|c|c|c|c|c|}
\hline & \multicolumn{3}{|c|}{ Delay (Asinh) } & \multicolumn{3}{|c|}{ Winning Discount } & \multicolumn{3}{|c|}{ Extra Cost } \\
\hline & (1) & $(2)$ & (3) & (4) & $(5)$ & (6) & (7) & $(8)$ & (9) \\
\hline investigated Firm & $\begin{array}{c}0.00286 \\
{[0.00350]}\end{array}$ & & & $\begin{array}{l}0.000646 \\
{[0.00200]}\end{array}$ & & & $\begin{array}{c}0.00531 \\
{[0.00350]}\end{array}$ & & \\
\hline Investigated RUP & & $\begin{array}{l}0.00920 \\
{[0.0121]}\end{array}$ & & & $\begin{array}{c}-0.000575 \\
{[0.00394]}\end{array}$ & & & $\begin{array}{c}-0.00588 \\
{[0.0115]}\end{array}$ & \\
\hline Investigated PA & & & $\begin{array}{c}-0.0356^{* * *} \\
{[0.0117]}\end{array}$ & & & $\begin{array}{c}-0.00934^{* * *} \\
{[0.00359]}\end{array}$ & & & $\begin{array}{l}-0.0159^{*} \\
{[0.00935]}\end{array}$ \\
\hline Constant & $\begin{array}{c}-0.281^{* * *} \\
{[0.0704]}\end{array}$ & $\begin{array}{c}-0.284^{* * *} \\
{[0.0704]}\end{array}$ & $\begin{array}{c}-0.106 \\
{[0.0649]}\end{array}$ & $\begin{array}{c}-0.336^{* * *} \\
{[0.0521]}\end{array}$ & $\begin{array}{c}-0.336^{* * *} \\
{[0.0520]}\end{array}$ & $\begin{array}{c}-0.372^{* * *} \\
{[0.0562]}\end{array}$ & $\begin{array}{l}-0.0595 \\
{[0.0538]}\end{array}$ & $\begin{array}{l}-0.0608 \\
{[0.0541]}\end{array}$ & $\begin{array}{l}-0.0569 \\
{[0.0548]}\end{array}$ \\
\hline Dep. Var. Mean & 0.487 & 0.487 & 0.487 & 0.0918 & 0.0918 & 0.0918 & 0.608 & 0.608 & 0.608 \\
\hline Observations & 155574 & 155574 & 155574 & 155574 & 155574 & 155574 & 155574 & 155574 & 155574 \\
\hline R-sq & 0.295 & 0.295 & 0.153 & 0.147 & 0.147 & 0.0577 & 0.290 & 0.290 & 0.163 \\
\hline
\end{tabular}

Note: The outcomes in this table are dummies for the presence of information on the outcomes used in Table 6. Regressions in columns (1), (2), (4), (5), (7), (8) include PA and Year fixed effects, a linear control for reserve price (in log) price and 5 dummies for different contract size thresholds (up to 100k, 100-150k, 150-300k, 300-500k, 500k-1mil, 1-1.5mil, over 1.5mil) as well as controls for contract characteristics: 4 dummies for category type (Civil Building, Roadworks, Specialized Works or Others), 1 dummy for whether the contract was awarded under urgency and 1 dummy for whether the object of the contract entailed maintenance. Regressions in columns (3), (6), (9) include Region instead of PA fixed effects as the main regressor only varies at the PA level. Robust standard errors clustered at the PA level are in parentheses. ${ }^{*} p<0.1,{ }^{* *} p<0.05,{ }^{* * *} p<0.01$. 
Table A12: Auction-level regressions, subsample of auctions with outcomes' data

\begin{tabular}{|c|c|c|c|c|c|c|c|c|c|c|}
\hline & \multicolumn{5}{|c|}{ all } & \multicolumn{5}{|c|}{ cities } \\
\hline & $(1)$ & $(2)$ & $(3)$ & (4) & $(5)$ & (6) & $(7)$ & $(8)$ & (9) & (10) \\
\hline DiscretCrit & $\begin{array}{l}0.0168^{* * *} \\
{[0.00585]}\end{array}$ & & $\begin{array}{l}0.0179^{* * *} \\
{[0.00585]}\end{array}$ & $\begin{array}{l}0.0178^{* * *} \\
{[0.00586]}\end{array}$ & & $\begin{array}{l}0.0254^{* * *} \\
{[0.00733]}\end{array}$ & & $\begin{array}{l}0.0266^{* * *} \\
{[0.00730]}\end{array}$ & $\begin{array}{l}0.0266^{* * *} \\
{[0.00737]}\end{array}$ & \\
\hline $\operatorname{DiscretProc}_{\text {low }}$ & & $\begin{array}{l}0.0278^{* * *} \\
{[0.00774]}\end{array}$ & $\begin{array}{l}0.0291^{\text {*** }} \\
{[0.00777]}\end{array}$ & $\begin{array}{l}0.0293^{* * *} \\
{[0.00803]}\end{array}$ & & & $\begin{array}{l}0.0279^{* * *} \\
{[0.00887]}\end{array}$ & $\begin{array}{l}0.0302^{* * *} \\
{[0.00890]}\end{array}$ & $\begin{array}{l}0.0302^{* * *} \\
{[0.00898]}\end{array}$ & \\
\hline DiscretProc $_{h i g h N}$ & & & & $\begin{array}{c}-0.000638 \\
{[0.00520]}\end{array}$ & $\begin{array}{c}0.00111 \\
{[0.00505]}\end{array}$ & & & & $\begin{array}{r}-0.000131 \\
{[0.00693]}\end{array}$ & $\begin{array}{l}0.000603 \\
{[0.00675]}\end{array}$ \\
\hline Discretion & & & & & $\begin{array}{l}0.0211^{* * *} \\
{[0.00491]}\end{array}$ & & & & & $\begin{array}{l}0.0299^{* * *} \\
{[0.00599]}\end{array}$ \\
\hline Dep. Var. Mean & 0.161 & 0.161 & 0.161 & 0.161 & 0.161 & 0.161 & 0.161 & 0.161 & 0.161 & 0.161 \\
\hline Observations & 66458 & 66458 & 66458 & 66458 & 66458 & 37311 & 37311 & 37311 & 37311 & 37311 \\
\hline R-sq & 0.145 & 0.145 & 0.145 & 0.145 & 0.145 & 0.165 & 0.165 & 0.165 & 0.165 & 0.165 \\
\hline
\end{tabular}

Note: This table is analogous to Table 4, but restricting the sample to the subset of auctions for which we have information on the outcomes used in Table 6. In all specifications, the dependent variable is an indicator equal to 1 if an investigated firm is awarded the contract. DiscretProc denotes negotiated procedures. DiscretProc low $_{N}$ denotes negotiated procedures with fewer than the legally mandated number of bidders. DiscretCrit denotes scoring rule auctions. Discretion denotes auctions for which either DiscretProc ${ }_{l o w N}=1$ or DiscretCrit=1. All regressions include PA and Year fixed effects, a linear control for reserve price (in log) price and 5 dummies for different contract size thresholds (up to 100k, 100-150k, 150-300k, 300-500k, 500k-1mil, 1-1.5mil, over 1.5mil) as well as controls for contract characteristics: 4 dummies for category type (Civil Building, Roadworks, Specialized Works or Others), 1 dummy for whether the contract was awarded under urgency and 1 dummy for whether the object of the contract entailed maintenance. Robust standard errors clustered at the PA level are in parentheses. ${ }^{*} p<0.1,{ }^{* *} p<0.05,{ }^{* * *} p<0.01$.

Table A13: Auction-level regressions, outcomes (municipalities only)

\begin{tabular}{|c|c|c|c|c|c|c|c|c|c|}
\hline & \multicolumn{3}{|c|}{ Delay (Asinh) } & \multicolumn{3}{|c|}{ Winning Discount } & \multicolumn{3}{|c|}{ Extra Cost } \\
\hline & (1) & $(2)$ & $(3)$ & $(4)$ & $(5)$ & (6) & $(7)$ & $(8)$ & $(9)$ \\
\hline Discretion & $\begin{array}{c}-0.156^{* * *} \\
{[0.0508]}\end{array}$ & & & $\begin{array}{c}-4.313^{* * *} \\
{[0.388]}\end{array}$ & & & $\begin{array}{c}-0.530^{*} \\
{[0.272]}\end{array}$ & & \\
\hline DiscretProc $_{l o w N}$ & & $\begin{array}{c}-0.462^{* * *} \\
{[0.0825]}\end{array}$ & $\begin{array}{c}-0.334^{* * *} \\
{[0.0862]}\end{array}$ & & $\begin{array}{c}-3.153^{* * *} \\
{[0.571]}\end{array}$ & $\begin{array}{c}-2.418^{* * *} \\
{[0.401]}\end{array}$ & & $\begin{array}{c}0.276 \\
{[0.438]}\end{array}$ & $\begin{array}{c}0.242 \\
{[0.428]}\end{array}$ \\
\hline DiscretCrit & & $\begin{array}{l}-0.0417 \\
{[0.0601]}\end{array}$ & $\begin{array}{l}-0.0586 \\
{[0.0595]}\end{array}$ & & $\begin{array}{c}-4.667^{* * *} \\
{[0.316]}\end{array}$ & $\begin{array}{c}-4.829^{* * *} \\
{[0.342]}\end{array}$ & & $\begin{array}{c}-0.776^{* *} \\
{[0.301]}\end{array}$ & $\begin{array}{r}-0.768^{* *} \\
{[0.310]}\end{array}$ \\
\hline DiscretProc $_{h i g h N}$ & & & $\begin{array}{c}-0.358^{* * *} \\
{[0.0626]}\end{array}$ & & & $\begin{array}{c}-2.105^{* * *} \\
{[0.601]}\end{array}$ & & & $\begin{array}{c}0.108 \\
{[0.309]} \\
\end{array}$ \\
\hline Dep. Var. Mean & 3.296 & 3.296 & 3.296 & 18.11 & 18.11 & 18.11 & 7.035 & 7.035 & 7.035 \\
\hline Observations & 58071 & 58071 & 58071 & 104628 & 104628 & 104628 & 46276 & 46276 & 46276 \\
\hline R-sq & 0.260 & 0.260 & 0.261 & 0.437 & 0.439 & 0.442 & 0.249 & 0.249 & 0.249 \\
\hline
\end{tabular}

Note: The dependent variable is indicated on top of each column. Delay is the inverse hyperbolic sine transformation of the number of days between the expected contractual duration and the effective total completion time. Winning Discount is the final price of the winning bid expressed as a discount over the reserve price (Discount) and Extra Cost represents excess completion costs, calculated as the difference between the final price and awarding price, over the initial reserve price. DiscretProc denotes negotiated procedures. DiscretProc ${ }_{l o w N}$ denotes negotiated procedures with fewer than the legally mandated number of bidders. DiscretCrit denotes scoring rule auctions. Discretion denotes auctions for which either DiscretProc ${ }_{l o w N}=1$ or DiscretCrit=1. All regressions include PA and Year fixed effects, a linear control for reserve price (in log) price and 5 dummies for different contract size thresholds (up to 100k, 100-150k, 150-300k, 300-500k, 500k1mil, 1-1.5mil, over 1.5mil) as well as controls for contract characteristics: 4 dummies for category type (Civil Building, Roadworks, Specialized Works or Others), 1 dummy for whether the contract was awarded under urgency and 1 dummy for whether the object of the contract entailed maintenance. Robust standard errors clustered at the PA level are in parentheses. ${ }^{*} p<0.1,{ }^{* *} p<0.05,{ }^{* * *} p<0.01$. 
Table A14: Auction-level regressions, direct effect of Investigated RUP and Investigated winner on outcomes

\begin{tabular}{|c|c|c|c|c|c|c|c|c|c|}
\hline & \multicolumn{3}{|c|}{ Delay (Asinh) } & \multicolumn{3}{|c|}{ Winning Discount } & \multicolumn{3}{|c|}{ Extra Cost } \\
\hline & (1) & (2) & (3) & (4) & (5) & (6) & (7) & $(8)$ & (9) \\
\hline Investigated Firm & $\begin{array}{c}-0.00965 \\
{[0.0337]}\end{array}$ & & $\begin{array}{c}-0.00419 \\
{[0.0343]}\end{array}$ & $\begin{array}{c}-0.460^{* * * *} \\
{[0.0776]}\end{array}$ & & $\begin{array}{c}-0.471^{* * *} \\
{[0.0783]}\end{array}$ & $\begin{array}{c}-0.233^{*} \\
{[0.138]}\end{array}$ & & $\begin{array}{c}-0.264^{*} \\
{[0.140]}\end{array}$ \\
\hline Investigated RUP & & $\begin{array}{l}-0.0743 \\
{[0.0771]}\end{array}$ & $\begin{array}{l}-0.0764 \\
{[0.0776]}\end{array}$ & & $\begin{array}{c}-0.734^{* * *} \\
{[0.223]}\end{array}$ & $\begin{array}{c}-0.731^{* * *} \\
{[0.224]}\end{array}$ & & $\begin{array}{c}0.198 \\
{[0.318]}\end{array}$ & $\begin{array}{c}0.159 \\
{[0.319]}\end{array}$ \\
\hline Constant & $\begin{array}{c}-5.360^{* * *} \\
{[0.678]}\end{array}$ & $\begin{array}{c}-5.659^{* * *} \\
{[0.682]}\end{array}$ & $\begin{array}{c}-5.436^{* * *} \\
{[0.690]}\end{array}$ & $\begin{array}{c}6.713^{* * *} \\
{[2.417]}\end{array}$ & $\begin{array}{c}10.21^{* * *} \\
{[2.725]}\end{array}$ & $\begin{array}{c}7.875^{* * *} \\
{[2.343]}\end{array}$ & $\begin{array}{c}-7.139^{* *} \\
{[3.392]}\end{array}$ & $\begin{array}{c}-6.798^{* *} \\
{[3.293]}\end{array}$ & $\begin{array}{r}-7.406^{* *} \\
{[3.415]}\end{array}$ \\
\hline $\begin{array}{l}\text { Dep. Var. Mean } \\
\text { Observations } \\
\text { R-sq }\end{array}$ & $\begin{array}{c}3.296 \\
101346 \\
0.249\end{array}$ & $\begin{array}{c}3.296 \\
105102 \\
0.249\end{array}$ & $\begin{array}{c}3.296 \\
99400 \\
0.248\end{array}$ & $\begin{array}{c}18.11 \\
180469 \\
0.435\end{array}$ & $\begin{array}{c}18.11 \\
187674 \\
0.429\end{array}$ & $\begin{array}{c}18.11 \\
177123 \\
0.434\end{array}$ & $\begin{array}{c}7.035 \\
77015 \\
0.222\end{array}$ & $\begin{array}{c}7.035 \\
79984 \\
0.219\end{array}$ & $\begin{array}{l}7.035 \\
75570 \\
0.223\end{array}$ \\
\hline
\end{tabular}

Note: The dependent variable is indicated at the top of each column. Delay is the inverse hyperbolic sine transformation of the number of days between the expected contractual duration and the effective total completion time. Winning Discount is the final price of the winning bid expressed as a discount over the reserve price (Discount) and ExtraCost represents excess completion costs, calculated as the difference between the final price and awarding price, over the initial

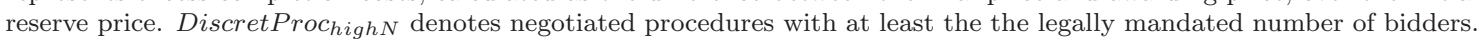
DiscretProclowN denotes negotiated procedures with fewer than the legally mandated number of bidders. DiscretCrit denotes scoring rule auctions. Discretion denotes auctions for which either DiscretProc low $N=1$ or DiscretCrit=1. All regressions include PA and Year fixed effects, a linear control for reserve price (in log) Price and 5 dummies for different contract size thresholds (up to $100 \mathrm{k}, 100-150 \mathrm{k}, 150-300 \mathrm{k}, 300-500 \mathrm{k}, 500 \mathrm{k}-1 \mathrm{mil}, 1-1.5 \mathrm{mil}$, over $1.5 \mathrm{mil}$ ) as well as controls for contract characteristics: 4 dummies for category type (Civil Building, Roadworks, Specialized Works or Others), 1 dummy for whether the contract was awarded under urgency and 1 dummy for whether the object of the contract entailed maintenance. Robust standard errors clustered at the PA level are in parentheses. ${ }^{*} p<0.1,{ }^{* *} p<0.05,{ }^{* * *} p<0.01$. 


\section{B Additional Details on the Investigations Data}

1. The source of the procurement data is the Public Contracts Observatory at the Italian Anticorruption Authority (ANAC). We accessed these data through a direct request to the Observatory, but the data have recently (September 2020) been made available as open data through the portal accessible here: https://dati. anticorruzione.it/opendata/dataset. The portal lists all of the datasets available. To replicate our data, a researcher needs to select contracts for public works involving either civic buildings (code: OG01), or transportation infrastructure such as roads, highways, and bridges (code: OG03) and then select the following variables: the start and end date of the bidding process, the identity and type of contracting authority, the auction procedure used to award the contract, the selection criterion, the number of bidders (both invited and participating), the identity of the winning bidder, initial project value, the winning discount, the total effective costs, and the expected and effective contractual duration. The identity of the RUP in charge of each contract is considered sensitive information and must be obtained through an ad hoc request to the Observatory motivated by research purposes. Similarly, the full list of firms participating in the auction is sensitive information and must be requested to the Observatory as the list of firms paying for the bidding fee ("contributo partecipazione").

2. The source of information on firm owners and managers is the Company Accounts Data System, a proprietary database maintained by a private company, the CERVED Group. Among the procurement data described above, the dataset "aggiudicatari" contains for each contract the name and social security number ("codice fiscale") of the winner. The latter variable uniquely identifies firms in the Company Accounts Data System and can thus be used to retrieve information on the identity of their owners and managers. ${ }^{1}$ We used the data observed for four separate years: 2006, 2011, 2014 and 2016. For each firm, the union of all owners and managers recorded in any of these four periods represents the set of individuals connected to the firm in our analysis. We performed the same procedure also for the firms participating in the auction. Access to the Company Accounts Data System is available for a fee from the CERVED Group by contacting:

\footnotetext{
${ }^{1}$ More precisely, we consider all of the individuals who either own shares of the firm or occupy at least one of the positions monitored by CERVED: the board of directors, auditors, general managers, and the heads of legal technical offices (the main roles are: AMMINISTRATORE; AMMINISTRATORE DELEGATO; AMMINISTRATORE UNICO; CONSIGLIERE; CONSIGLIERE DELEGATO; CURATORE FALLIMENTARE; DELEGATO AL RITIRO CAPITALE VERSATO; DIRETTORE GENERALE; DIRETTORE TECNICO; INSTITORE; LEGALE RAPPRESENTANTE; PRESIDENTE; PRESIDENTE DEL COLLEGIO SINDACALE; PROCURATORE; RESPONSABILE TECNICO; SINDACO; SOCIO)
} 
https://www. cerved-online.com/contatti.

3. Information on the identities of firm owners and managers (and also RUPs' identities) were used to retrieve their records of criminal investigations from which, by aggregating up at the firm level, flags were created for firms with at least one firmlinked person under investigation. We could not directly link individuals to their criminal records, and thus the process of generating firm-level flags for firms linked to investigated individuals was performed by AISI, Italys internal intelligence and security agency. Our access to the data is enabled via an agreement between AISI and Bocconi University. AISI used a centralized archive, the Sistema DIndagine Interforze (SDI) Centro Elaborazione Dati (CED), which is a primary source of information that police officers and intelligence agencies use to identify potential targets for further investigation (https://www.poliziadistato.it/articolo/37262), at all four of the Italian police forces: state police (Polizia di Stato), finance police (Guardia di Finanza), military police (Carabinieri), and environmental police (Guardia Forestale).

The staff of the Police Forces is required by law (Art. 16 L. 121/81) to send to the SDI, without delay, any information acquired through "administrative activities" or "activities of prevention or repression of crimes." Hence the SDI must cover information on every investigation undertaken by the police forces. For an individual, the first entry in the SDI database for a particular allegation occurs when a police force, based on a preliminary investigation, determines that there is sufficient evidence to open a formal investigation. See Figure A.2.

Hence, based on the list of individuals that we communicated to the AISI, it created a sample of suspect offenders, including those individuals that were convicted, acquitted, or never charged (but nonetheless investigated) for the following crimes: corruption, malfeasance and embezzlement; abuse of power and undue influence; and violations in public auctions.

The SDI data also allow us to flag RUPs who are under investigation for corruption and related charges. By flagging these RUPs we can also determine which procuring agencies are suspect (i.e., those employing at least one suspect RUP). 